\title{
Four new species of the subfamily Candoninae (Crustacea, Ostracoda) from freshwater habitats in Japan
}

\author{
Robin James SMITH ${ }^{1} \&$ Takahiro KAMIYA ${ }^{2}$ \\ ${ }^{1}$ Lake Biwa Museum, 1091 Oroshimo, Kusatsu, Shiga 525-0001, Japan. \\ Email: smith@lbm.go.jp (corresponding author) \\ ${ }^{2}$ College of Science and Engineering, School of Natural System, University of Kanazawa, \\ Kakuma, Kanazawa 920-1192, Japan. \\ ${ }^{1}$ urn:1sid:zoobank.org:author:D63C5DD6-C0BB-43EA-8D2F-98134CC29188 \\ ${ }^{2}$ urn:1sid:zoobank.org:author:5FB5FC58-0FBF-45DA-9FDC-7569BDA1FDF9
}

\begin{abstract}
Three species of the genus Pseudocandona Kaufmann, 1900 and one of the genus Undulacandona Smith, 2011, collected from freshwater habitats in Japan, are described. The Pseudocandona species, Pseudocandona becca sp. nov., Pseudocandona atmeta sp. nov. and Pseudocandona falcula sp. nov., all belong to the rostrata-group. Previous reports of Pseudocandona rostrata (Brady \& Norman, 1889) and Pseudocandona sarsi (Hartwig, 1899) from Japan are reassessed and are subsequently synonymized with Pseudocandona tenuirostris Hiruta \& Mawatari, 2013 and Pseudocandona falcula sp. nov. respectively. Undulacandona colymba sp. nov. is only the second to be described in this genus. Like the type species of the genus, it is a stygobiont, collected from groundwater in Shiga Prefecture. Additional records of Candona candida (O.F. Müller, 1776), are presented herein; so far, Japanese records of this species are restricted to the eastern part of Hokkaido.
\end{abstract}

Keywords. Taxonomy, Candoninae, Pseudocandona, Undulacandona, Japan.

Smith R.J. \& Kamiya T. 2015. Four new species of the subfamily Candoninae (Crustacea, Ostracoda) from freshwater habitats in Japan. European Journal of Taxonomy 136: 1-34. http://dx.doi.org/10.5852/ejt.2015.136

\section{Introduction}

The family Candonidae, consisting of the subfamilies Candoninae, Cyclocypridinae and Paracypridinae, is the second most diverse group of freshwater ostracods, with approximately $95 \%$ of species endemic to particular zoogeographical provinces (Martens et al. 2008). In the largest Candonidae subfamily, the Candoninae, there are at least 511 species in 37 genera (data extracted from the checklist of Martens \& Savatenalinton 2011). In Japan, 24 species of this subfamily have been reported, half of which belong to the genus Fabaeformiscandona Krstić, 1972 (Okubo 1990, 2004; Matzke-Karasz et al. 2004; Smith \& Kamiya 2006; Smith \& Janz 2008; Smith 2011; Hiruta \& Mawatari 2013; Tanaka et al. 2015). However, many undescribed Candoninae species exist in Japan, and the aims of this paper are to describe three species of the genus Pseudocandona Kaufmann, 1900, and one species of the genus Undulacandona Smith, 2011 that have been recovered during surveys of freshwater habitats. Additionally, some previous records of Candoninae in Japan are re-assessed in light of the newly acquired taxonomic data, and new records of two other species are presented. 
Martens \& Savatenalinton (2011) listed 85 extant species/subspecies of the genus Pseudocandona, mostly from the Palaearctic ( 73 species), with smaller numbers of species also found in the Nearctic (13 species), Neotropical (5 species) and Australasian (1 species) regions. About 30 species are endemic to Lake Baikal, although these may represent a different lineage from those outside of the lake and require revision (Danielopol et al. 2011). The genus previously consisted of six groups, but the zschokkei-group was transferred to a new genus (Danielopol et al. 2012), and a recent taxonomic revision moved the eremita-group, consisting of 14 species, to the genus Typhlocypris Vejdovský, 1882 (Namiotko et al. 2014). The affinities of two other groups, the carribeana- and prespica-groups, need to be reviewed, and so this leaves two groups, the compressa- and rostrata-groups, that are Pseudocandona sensu stricto (Namiotko et al. 2014). In North East Asia, described Pseudocandona species are relatively few in number, with only two species reported from China (see references in Yu et al. 2009), three from Korea (one of which was described in the genus Typhlocypris) (McKenzie 1972; Karanovic \& Lee

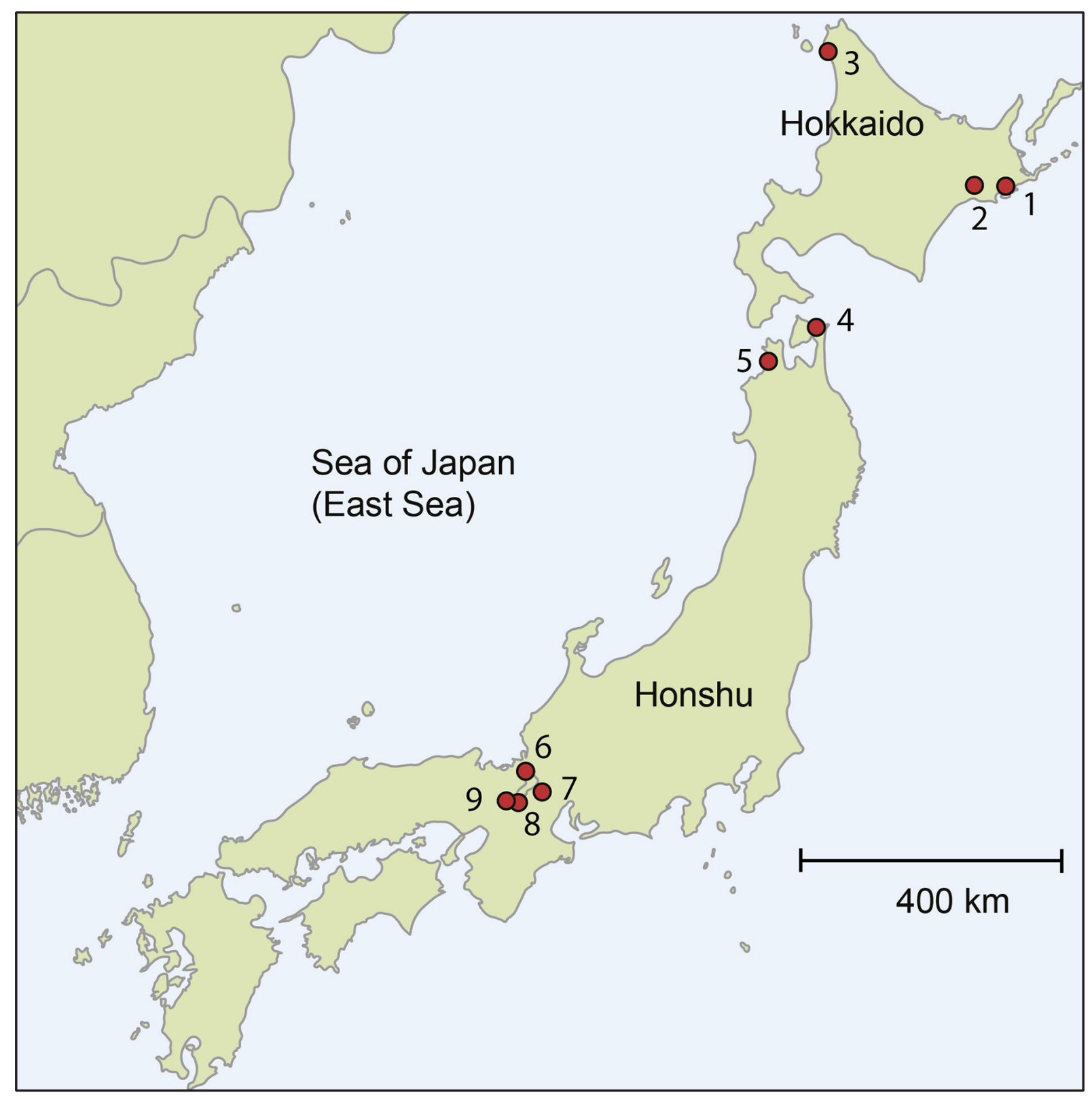

Fig. 1. Map of the main islands of Japan, showing the localities mentioned in the text. 
2012; Karanovic 2013), and five from Japan (Matzke-Karasz et al. 2004; Smith \& Janz 2008; Hiruta \& Mawatari 2013; Tanaka et al. 2015).

The genus Undulacandona was created to accommodate a single species of Candoninae recovered from groundwater below the city of Otsu, on the shores of the ancient Lake Biwa, Japan (Smith 2011). The highly unusual combination of characters of oversized seventh limbs (used for locomotion rather than cleaning), the male antennal morphology, and the reduced Zenker organs and caudal rami indicate that this genus is clearly a distinct lineage within the Candoninae. So far, this genus is only known from groundwater in Japan.

\section{Material and methods}

Specimens of Undulacandona were collected from an agricultural well with a hand pump installed. Vigorous pumping of the hand pump while holding a plankton net under the resulting water flow brought sandy sediment and specimens to the surface. Other species were collected by washing sediment from aquatic habitats through a $125 \mu \mathrm{m}$ sieve. The sample containing Undulacandona was picked while specimens were alive with the aid of a stereo microscope, but other samples were first fixed with ethanol prior to the picking out of specimens. In both cases, specimens were preserved in approximately $80 \%$ ethanol. Appendages were dissected and mounted in glycerol and drawn with the aid of a camera lucida. Carapaces are stored dry in micropalaeontological cavity slides. Carapaces used for SEM investigation were coated with gold before being photographed with a JEOL 5800 LV scanning electron microscope. Type material is deposited in the Lake Biwa Museum, Shiga Prefecture, Japan (numbers with prefix LBM).

Terminology of the appendage chaetotaxy follows that of Broodbakker \& Danielopol (1982), Martens (1987), and Meisch (2000). Note that caudal rami are referred to as furcae or uropods by some authors.

\section{Results}

Class Ostracoda Latreille, 1802

Subclass Podocopa G.W. Müller, 1894

Order Podocopida G.O. Sars, 1866

Suborder Cypridocopina Jones, 1901

Superfamily Cypridoidea Baird, 1845

Family Candonidae Kaufmann, 1900

Subfamily Candoninae Kaufmann, 1900

Genus Pseudocandona Kaufmann, 1900

For a diagnosis, see Higuti \& Martens (2014).

rostrata-group

Pseudocandona becca sp. nov.

urn:1sid:zoobank.org:act:F3A75D11-C834-4673-817D-E962EA9F9347

Figs 2A-E, 3-5, 6A

Pseudocandona sp. - Smith et al. 2014: appendix S1.

\section{Diagnosis}

Posterior margin more inflated than anterior margin, hinge straight, slightly sloping towards anterior. Calcified inner lamella with distinctive convexity in antero-ventral region. Dorsal view with slight anterior beak. Surface of valves without pits. Second endopodal segment of male antenna sub-divided 
and with long male bristles (t2 and $\mathrm{t} 3$ ). Female antennal claw G2 approximately two-thirds length of G3. Mandible with $3+1+$ beta setae on second segment of palp, and with long gamma seta and short alpha and beta setae; beta slightly shorter than alpha. Walking leg with long d1 seta, and very short e, $\mathrm{f}$ and $\mathrm{g}$ setae. Seventh limb with five segments, and short, curved, reflexed h1 seta and long h2 and h3 setae. Outer and inner lobes ( $a$ and $b$ respectively) of hemipenes sub-equal in length. Outer lobe (a) subquadrate distally, inner lobe (b) sub-triangular distally. Medial lobe (h) shorter than other lobes, with distinctive small, triangular to quadrate protrusion on outer edge.

\section{Etymology}

From the Latin beccus, meaning "beak" or "bill", and referring to the small but characteristic, beakshaped projection on the medial lobe (h) of the hemipenes (marked with a black triangle on Fig. 5C).

\section{Type material}

\section{Holotype}

ऽ (LBM 1430006264), dissected with appendages sealed in a glass slide and valves stored dry in a micropalaeontological cavity slide. Collected from the type locality on 5 Dec. 2010.

\section{Allotype}

q (LBM 1430006265), dissected with appendages sealed in a glass slide and valves stored dry in a micropalaeontological cavity slide. Collected from the type locality on 5 Dec. 2010.

\section{Paratypes}

2 우우 (LBM 1430006266, LBM 1430006267), dissected with appendages sealed in a glass slide and valves stored dry in a micropalaeontological cavity slide. 1 ( (LBM 1430006268), whole, stored dry in a micropalaeontological cavity slide. 1 (LBM 1430006269), valves, stored dry in a micropalaeontological cavity slide. All collected from the type locality on 5 Dec. 2010.

\section{Type locality}

Sunny Beach in Nishihama, Makino, Lake Biwa, Shiga Prefecture, Japan, 35²7'26.58” N, 136 03'49.5” E. Locality 6 on Fig. 1.

\section{Other material examined}

11 우, $6 \widehat{\partial}$, collected from the type locality on 5 Dec. 2010.

\section{Description}

Carapace (Figs 2A-E, 3A-B) length 1135-1181 $\mu \mathrm{m}$, height 547-594 $\mu \mathrm{m}$, female carapace slightly less high than male. Posterior margin more inflated than anterior margin, both margins unevenly curved, with maximum curvature below mid-height. Ventral margin slightly concave, dorsal margin straight, sloping down towards anterior. Dorsal view compressed, with anterior end slightly beak-shaped, posterior end slightly pointed. Calcified inner lamella wider anteriorly than posteriorly. Anterior calcified inner lamella not evenly curved but with convexity in the antero-ventral region, forming distinct wider section (marked with triangle on Fig 3A). Carapace delicate, with smooth surface. Colour translucent white.

Antennule with seven articulated segments (Fig. 3C). First segment large, supporting two setae on dorsal edge and two long setae on ventral-apical corner. Second and third segments quadrate, with one dorsal-apical seta each. Fourth and fifth segments each with two long dorsal-apical setae and one short ventral-apical seta. Sixth segment with three long and one short apical setae. Final segment with two long and one short setae, and aesthetasc ya. 

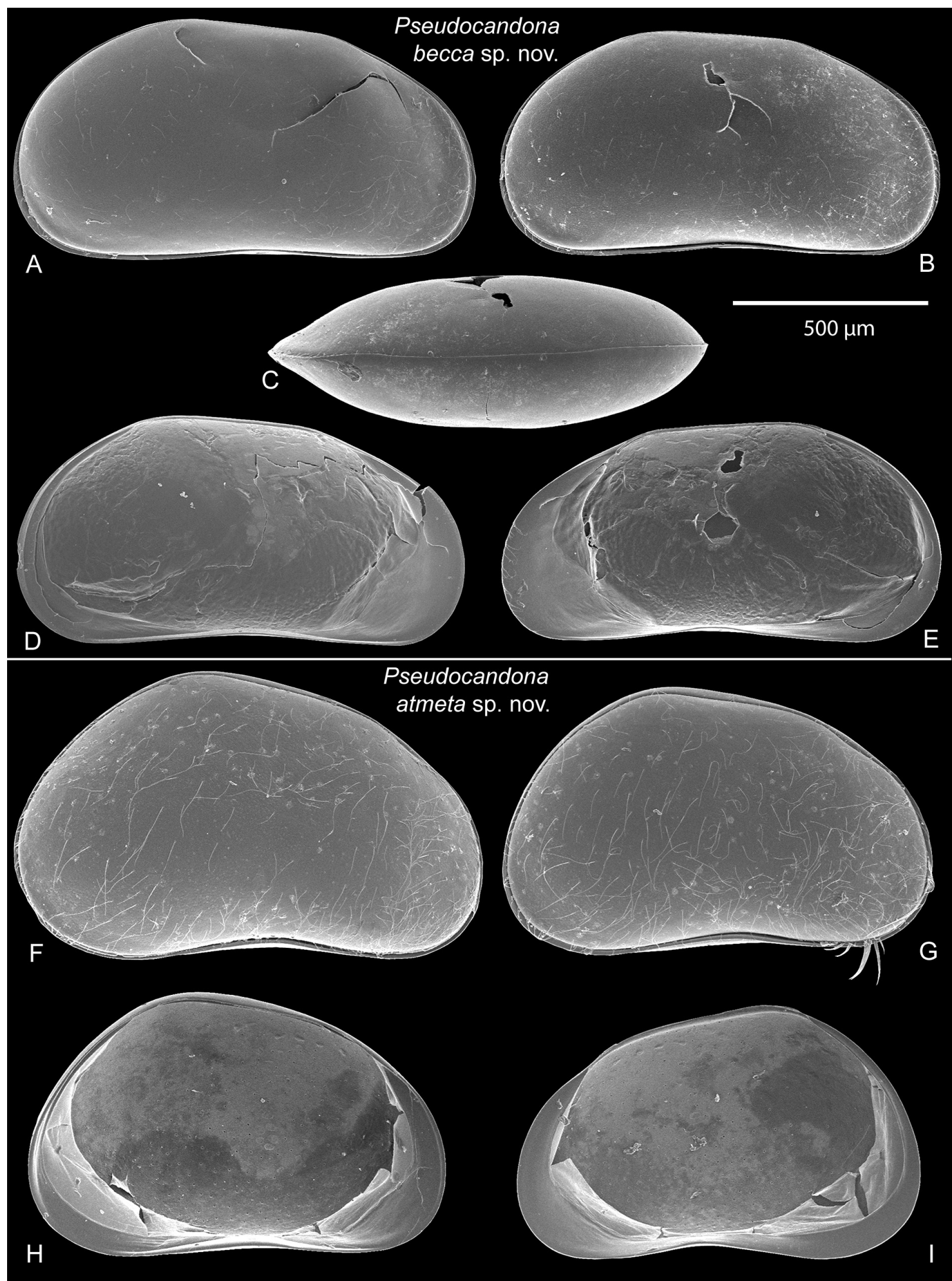

Fig. 2. A-E. Pseudocandona becca sp. nov. A. Right view of male carapace (LBM 1430006268). B. Right view of female carapace (LBM 1430006269). C. Dorsal view of female carapace, anterior to left (LBM 1430006269). D. Internal view of female left valve (LBM 1430006269). E. Internal view of female right valve (LBM 1430006269). F-I. Pseudocandona atmeta sp. nov. F. Right view of male carapace (LBM 1430006272). G. Right view of female carapace (LBM 1430006273). H. Internal view of female left valve (LBM 1430006274). I. Internal view of female right valve (LBM 1430006274). 

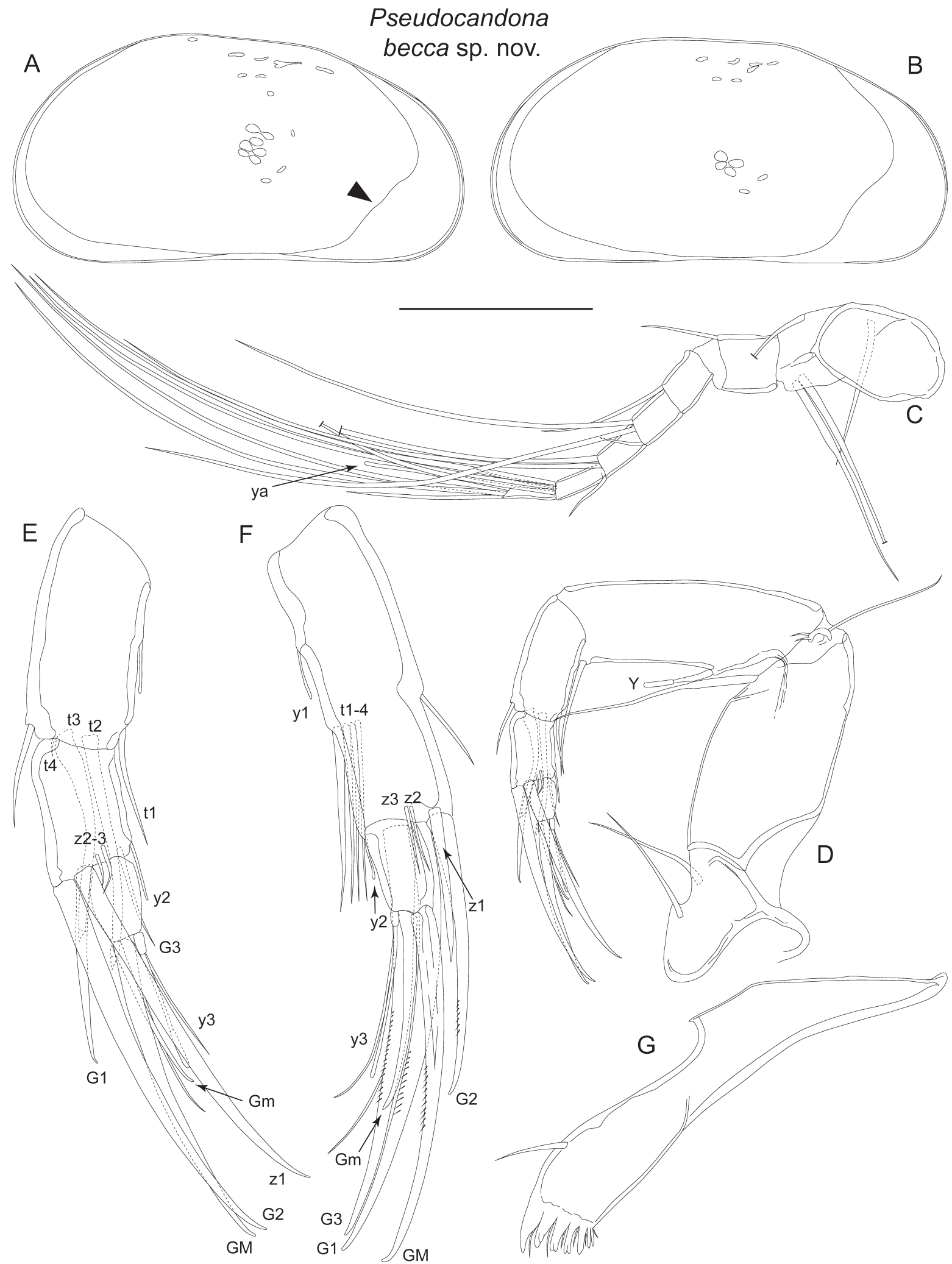

Fig. 3. Pseudocandona becca sp. nov. A. Internal view of male left valve. B. Internal view of female left valve (LBM 1430006266). C. Male antennule (LBM 1430006264). D. Male antenna (LBM 1430006264). E. Detail of male antenna (LBM 1430006264). F. Detail of female antenna (LBM 1430006266). G. Female mandibular coxa (LBM 1430006267). Scale bar: A-B $=500 \mu \mathrm{m} ; \mathrm{C}-\mathrm{D}, \mathrm{G}=127 \mu \mathrm{m}$; $\mathrm{E}-\mathrm{F}=66 \mu \mathrm{m}$. 


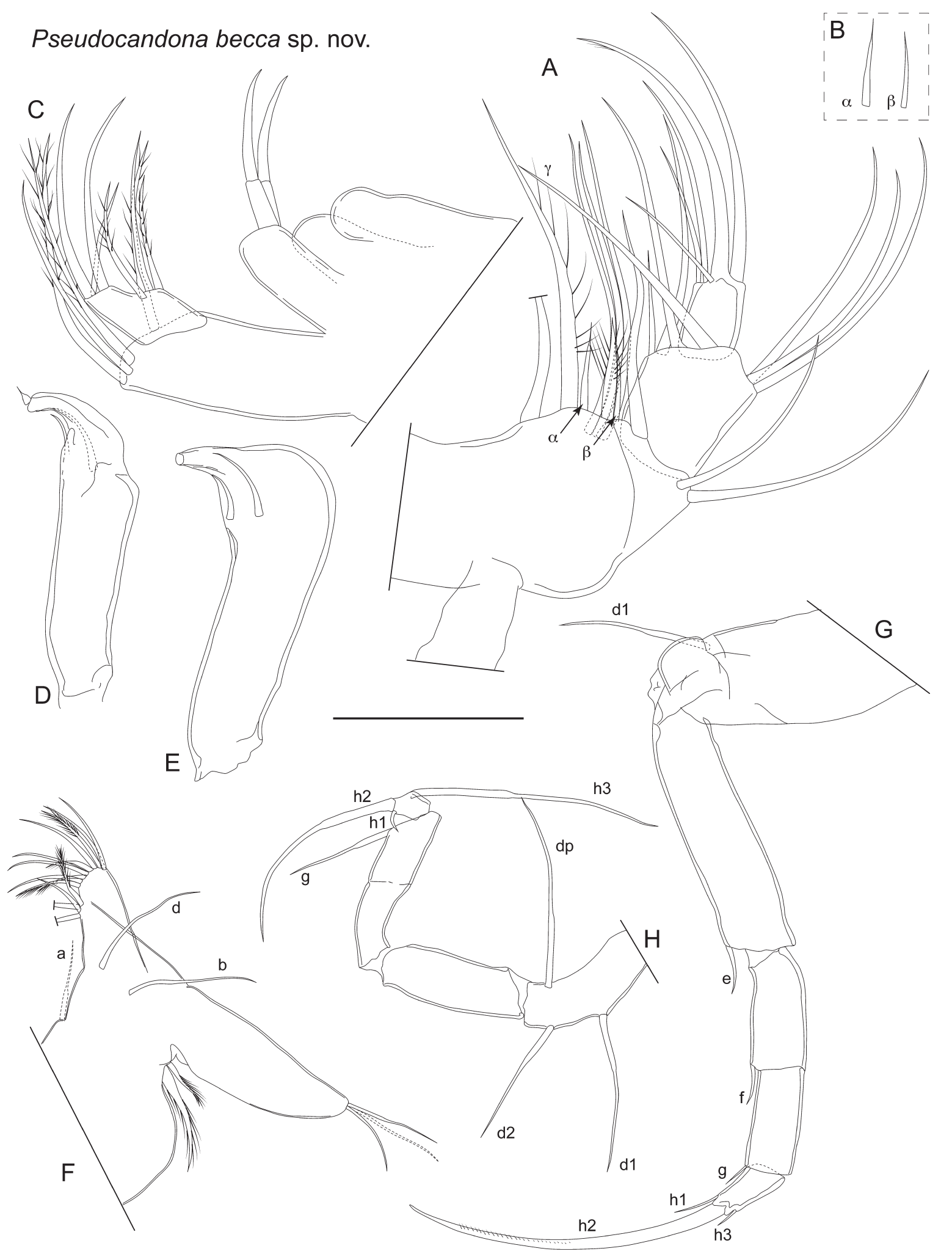

Fig. 4. Pseudocandona becca sp. nov. A. Female mandibular palp (LBM 1430006267). B. Alpha and beta setae of the mandibular palp (LBM 1430006267). C. Female maxillula (setae on endites not drawn) (LBM 1430006265). D-E. Left and right male fifth limb palps (LBM 1430006264). F. Female fifth limb (LBM 1430006265). G. Male sixth limb (LBM 1430006264). H. Male seventh limb (LBM 1430006264). Scale bar: $\mathrm{A}-\mathrm{C}=66 \mu \mathrm{m} ; \mathrm{D}-\mathrm{H}=127 \mu \mathrm{m}$. 
Male antenna with second endopodite segment sub-divided (Fig. 3D-E). Setae $\mathrm{t} 2$ and $\mathrm{t} 3$ represented by long male bristles, both similar in morphology, each terminating with small, triangular process. Seta $\mathrm{t} 4$ tiny, protruding from near base of $\mathrm{t} 3$. Setae $\mathrm{z} 2$ and z3 very short, $\mathrm{z} 1$ represented by well-developed claw, of similar size to claw G2. Claw G1 about half length of claw G2. Claw Gm on final segment half length of claw GM.

Female antennal (Fig. 3F) claw G2 about two-thirds length of G1, z1 stout and claw-like, about half length of G2, setae z2 and z3 very short. Claw Gm just over half length of claw GM. Exopodite of both sexes with longest seta relatively short, not reaching to end of first endopodal segment (Fig. 3D).

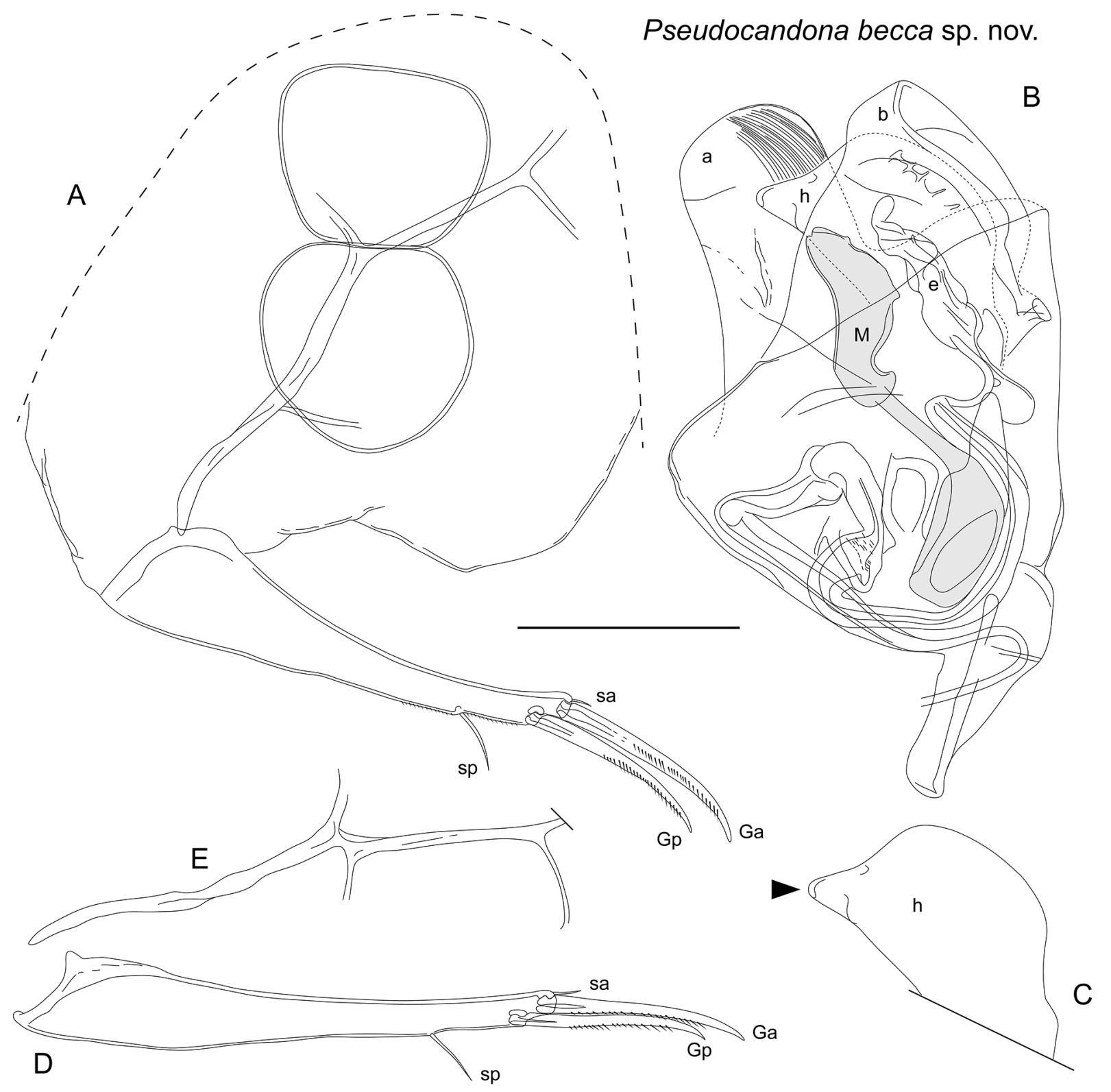

Fig. 5. Pseudocandona becca sp. nov. A. Caudal ramus and female genital lobe (LBM 1430006265). B. Hemipenis (LBM 1430006264). C. Detail of lobe h of hemipenis (LBM 1430006264), black triangle marks protrusion (see text for explanation). D. Male caudal ramus (LBM 1430006264). E. Male caudal ramus attachment (LBM 1430006264). Scale bar $=127 \mu \mathrm{m}$. 
Mandibular palp (Fig. 4A) with four segments. Alpha seta of first segment short (Fig. 4A-B). Inner edge of second segment with $3+1+$ beta arrangement of setae; beta seta slightly shorter than alpha (Fig. 4B). Outer edge of second segment with two apical setae. Third segment with three long sub-apical setae on outer edge, and three long and one short setae arranged along apical edge; outer-most gamma seta, long and without obvious setules. Final segment with robust seta on outer edge, thick claw-like seta in mid-apical position and three shorter setae on inner apical edge. Six long setae on branchial plate. Mandibular coxa (Fig. 3G) with five well-developed teeth plus two much smaller, spine-like teeth.

Maxillula (Fig. 4C) palp first segment with three setae on apical outer margin, and one apical seta offset towards inner edge. Second segment with stepped apical margin, with outer part more distal than inner part. Outer part of apical margin with two long and one mid-length setae, and inner part with three midlength setae. Branchial plate with morphology typical of subfamily, supporting 18-19 normals rays; number of reflexed rays not observed.

Fifth limb palps of male asymmetrical (Fig. 4D-E). Right palp widens distally to large bulbous hookshaped end, with two sub-apical setae towards inner edge. Left palp distally narrower than right, with finger-like distal hook, and with two sub-apical setae. Fifth limb of female (Fig. 4F) with long $d$ and b setae, and one a seta.

Sixth limb (Fig. 4G) five-segmented, with first segment bearing long d1 seta. Setae e and f of second and third segments respectively, both less than half length of next respective segment. Fourth segment with short g seta. Fifth segment with short h1 and h3 seta and well-developed claw h2.

Seventh limb (Fig. 4H) with five segments, but division between third and fourth segments weak. First segment with long d1, d2 and dp setae. Second and third segments with no setae. Fourth segment with long g seta. Final segment with two long setae (h2 and h3) and one short, reflexed, hooked setae (h1).

Caudal ramus (Fig. 5A, D) with inflated proximal end, tapering distally, slightly curved. Claw Gp approximately $90 \%$ length of claw Ga. Seta sa very short. Seta sp short, about $30 \%$ length of claw Gp.

Male sexual organ (Figs 5B, 6A) outer lobe (a) tongue-like, elongate with rounded end and striations towards distal edge. Inner lobe (b) wide, slightly sub-triangular, protruding just beyong outer lobe. Medial lobe (h) shorter than both outer and inner lobes, unevenly rounded with triangular to sub-quadrate process on outer edge (Fig. 5C). M-process with rounded proximal part tapering to thin, straight central part, and then expanding to large, elongate, roughly triangular distal part; inner edge with indentation towards base of distal part. Bursa copulatrix (e) elongate and irregular in shape, with distal-most part lobe-like and bent off-axis.

Female genital lobe (Fig. 5A) protruding, sub-triangular to rounded.

\section{Remarks}

Smith et al. (2014) reported that this species, as Pseudocandona sp., has sperm ranging from 424 to $475 \mu \mathrm{m}$ in length.

The combination of the calcified inner lamella with a distinctive convexity in the antero-ventral region of the carapace, the reflexed h1 seta on the seventh limb, and especially the morphology of the hemipenes clearly separate this species from its congeners.

The lateral view of the carapace is similar to that of Pseudocandona renoensis (Gutentag \& Benson, 1962) and Pseudocandona delormei (Karanovic, 2006). Pseudocandona renoensis was described from Pleistocene deposits in Kanas, USA (Gutentag \& Benson 1962), but later living specimens were reported 
from Canada (Delorme 1970). The lateral view of the female carapace of $P$. renoensis is similar to that of the female of Pseudocandona becca sp. nov., but the male is higher and more rounded posteriorly than the male of Pseudocandona becca sp. nov. Delorme's (1970) figure of $P$. renoensis shows a similar distinctive convexity in the antero-ventral region of the calcified inner lamella of the carapace to that of Pseudocandona becca sp. nov., but this feature is missing in Gutentag \& Benson's (1962) original description of $P$. renoensis.
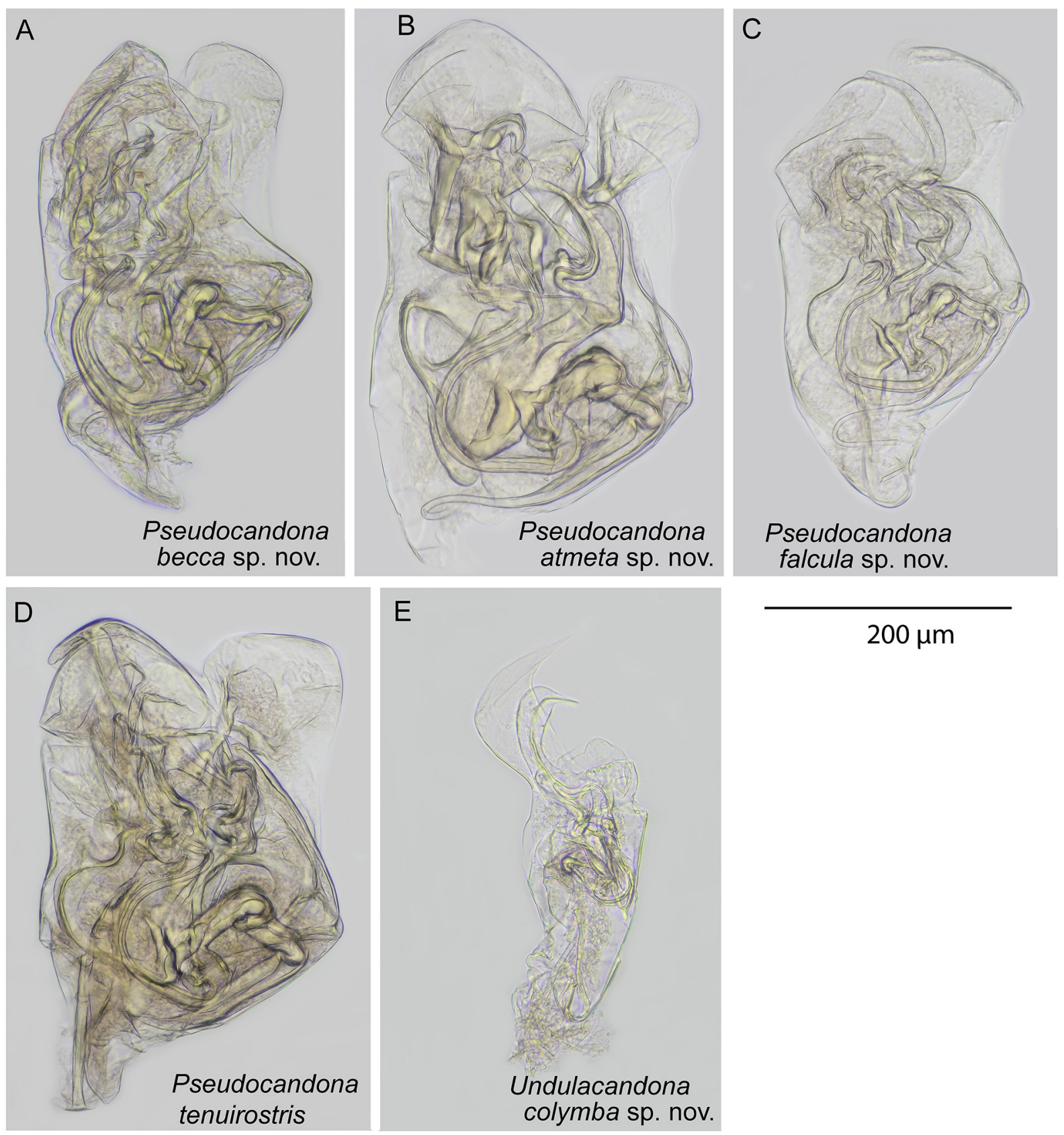

$200 \mu \mathrm{m}$

Fig. 6. A. Pseudocandona becca sp. nov. hemipenis (LBM 1430006264). B. Pseudocandona atmeta sp. nov. hemipenis (LBM 1430006270). C. Pseudocandona falcula sp. nov. hemipenis (LBM 1430006275). D. Pseudocandona tenuirostris Hiruta \& Mawatari, 2013 hemipenis. E. Undulacandona colymba sp. nov. hemipenis (LBM 1430006279). 
Pseudocandona delormei was erected by Karanovic (2006) based on photographs of Pseudocandona hartwigi (G.W. Müller, 1900) and Pseudocandona sarsi (Hartwig, 1899) in Delorme (1970). Delorme's specimens of Pseudocandona sarsi were designated by Karanovic (2006) as the type material of $P$. delormei, even though she was unable to trace this material. Karanovic's (2006) opinion that the specimens of Pseudocandona hartwigi and Pseudocandona sarsi figured by Delorme (1970) are the same species is probably incorrect, as the lateral views of the valves of both species are different in Delorme's figures. Pseudocandona hartwigi figured by Delorme (1970) has an distinctive convexity in the antero-ventral region of the calcified inner lamella, similar to that of Pseudocandona becca sp. nov. (absent in Pseudocandona sarsi and other reports of Pseudocandona hartwigi), but the carapace in lateral view is noticeably higher than that of Pseudocandona becca sp. nov. and the hemipenes are also differently shaped.

\section{Ecology and distribution}

So far, this species is only known from the type locality. The species was found by digging a small, shallow hole in the sand at the water's edge (psammon environment) of the beach at Makino in the north-western part of Lake Biwa.

\section{Pseudocandona atmeta sp. nov. urn:lsid:zoobank.org:act:CE81B0CC-F7FD-46EF-87DD-CCD6907068ED}

Figs 2F-I, 6B, 7A-B, 8-10

\section{Diagnosis}

Carapace relatively large (approximately $1.2 \mathrm{~mm}$ in length) and high (height/length $=0.67$ ), with maximum height posterior of mid-length, marked by dorsal hump. Hinge slightly curved anterior of dorsal hump, steeply sloping down towards anterior margin. Male antenna with undivided second endopodal segment, and with no male bristles. Female antennal claw G2 approximately half length of claw G3. Mandible with $3+1+$ beta setae on second segment of palp, and with long gamma seta and very short alpha and beta setae; beta slightly shorter than alpha. Walking leg with long d1 seta, and with e, and $f$ setae shorter than next segment respectively. Seventh limb with five segments, terminating with long h2 and h3 setae of approximately equal length, and short, reflexed and curled h1 seta. Medial lobe (h) of hemipenis extending beyond outer lobe (a); outer lobe distally sub-quadrate, inner lobe (b) folded at inner edge. Female genital lobe triangular in shape with apical protuberance.

\section{Etymology}

From the Greek atmetos, meaning "undivided", and referring to the second endopodal segment of the male antenna, which is undivided in this species.

\section{Type material}

\section{Holotype}

(LBM 1430006270), dissected with appendages sealed in a glass slide and valves stored dry in a micropalaeontological cavity slide. Collected from the type locality on 27 Sep. 2004.

\section{Allotype}

q (LBM 1430006271), dissected with appendages sealed in a glass slide and valves stored dry in a micropalaeontological cavity slide. Collected from the type locality on 27 Sep. 2004.

\section{Paratypes}

$1 \delta$ (LBM 1430006272), whole, stored dry in a micropalaeontological cavity slide. 1 q (LBM 1430006273) whole, stored dry in a micropalaeontological cavity slide. 1 \& (LBM 1430006274) valves, stored dry in a micropalaeontological cavity slide. All collected from the type locality on 27 Sep. 2004. 


\section{Type locality}

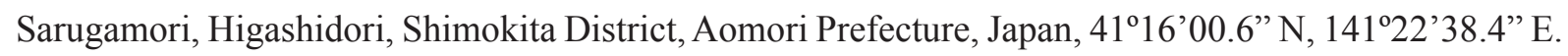
Boggy, marshy area with little standing water, lots of reeds, and sodden ground. Locality 4 on Fig. 1 .

\section{Other material examined}

$68 \hat{\jmath} \hat{0}, 33$ 우, from the type locality, collected 27 Sep. 2004. 1 ô from a small swampy area surrounded by trees, reeds and moss at Higashidori, Shimokita District, 12.

\section{Description}

Carapace (Figs 2F-I, 7A-B, 8A-B). Male length 1137-1227 $\mu \mathrm{m}$, height 657-760 $\mu \mathrm{m}$. Female length 1028-1157 $\mu \mathrm{m}$, height $631-689 \mu \mathrm{m}$. Male with distinctive dorsal hump posterior of mid-length. Hinge slightly curved anterior of dorsal hump, steeply sloping down towards anterior margin. Anterior margin unevenly curved, with apex of curve below mid-height. Posterior margin more inflated than anterior margin and unevenly curved, with apex below mid-height. Ventral margin slightly concave. Dorsal view ovoid, anterior slightly more pointed than posterior. Inner calcified lamella wide anteriorly and narrow posteriorly, narrowest along posterior margin, widening slightly at postero-ventral margin. Six to seven small adductor muscle scars in tight formation at mid-height, anterior of mid-length. Indistinct dorsal scars near dorsal margin. Female similar to male, but slightly less elongate. Colour, white. Surface covered with stiff setae and small, shallow pits (observed with scanning electron microscopy) (Fig. 7B).

Antennule with seven articulated segments (Fig. 8C). First segment large, supporting two setae on dorsal edge and two long setae on ventral-apical corner. Second and third segments quadrate each with one dorsal-apical seta each. Fourth and fifth segments each with two long dorsal-apical setae and one short ventral-apical seta. Sixth segment with two long and two short apical setae. Final segment with two long and one short setae, and aesthetasc ya.

Male antenna with three-segmented endopodite (second endopodal segment not divided and with no male bristles) (Fig. 8D-E). Setae z2 and z3 very short. Claw G1 about half length of claw G2 and z1. Claw Gm on final segment half length of claw GM.

Female antenna (Fig. 8F) with claw G2 about half length of G1, z1 stout and claw-like, about half length of G2, setae z2 and z3 very short. Claw Gm approximately three-fourths length of claw GM.

Mandibular palp (Figs 8G, 9A \& B) with four segments. Alpha and beta setae very small, sub-equal in length. Inner edge of second segment with $3+1+$ beta arrangement of setae. Outer edge with two apical setae. Third segment with three long sub-apical setae on outer edge, and three long and one short setae arranged along apical edge; outer-most gamma seta, long and without obvious setules. Final segment with two claws and three setae. Number of rays on branchial plate not observed.

Maxillula (Fig. 9C) palp first segment with three setae on apical outer margin, and one apical seta offset towards inner edge. Second segment with stepped apical margin, with outer part more distal than inner part. Outer part of apical margin with two long and one short setae, and inner part with three mid-length setae. Branchial plate with morphology typical of subfamily, consisting of 18 normal and six reflexed rays.

Fifth limb palps of male asymmetrical (Fig. 9E-F). Right palp widens distally to large bulbous hookshaped end, with two sub-apical setae towards inner edge. Left palp distally narrower than right, sinuous, with finger-like, crooked distal hook, and with two sub-apical seta. 

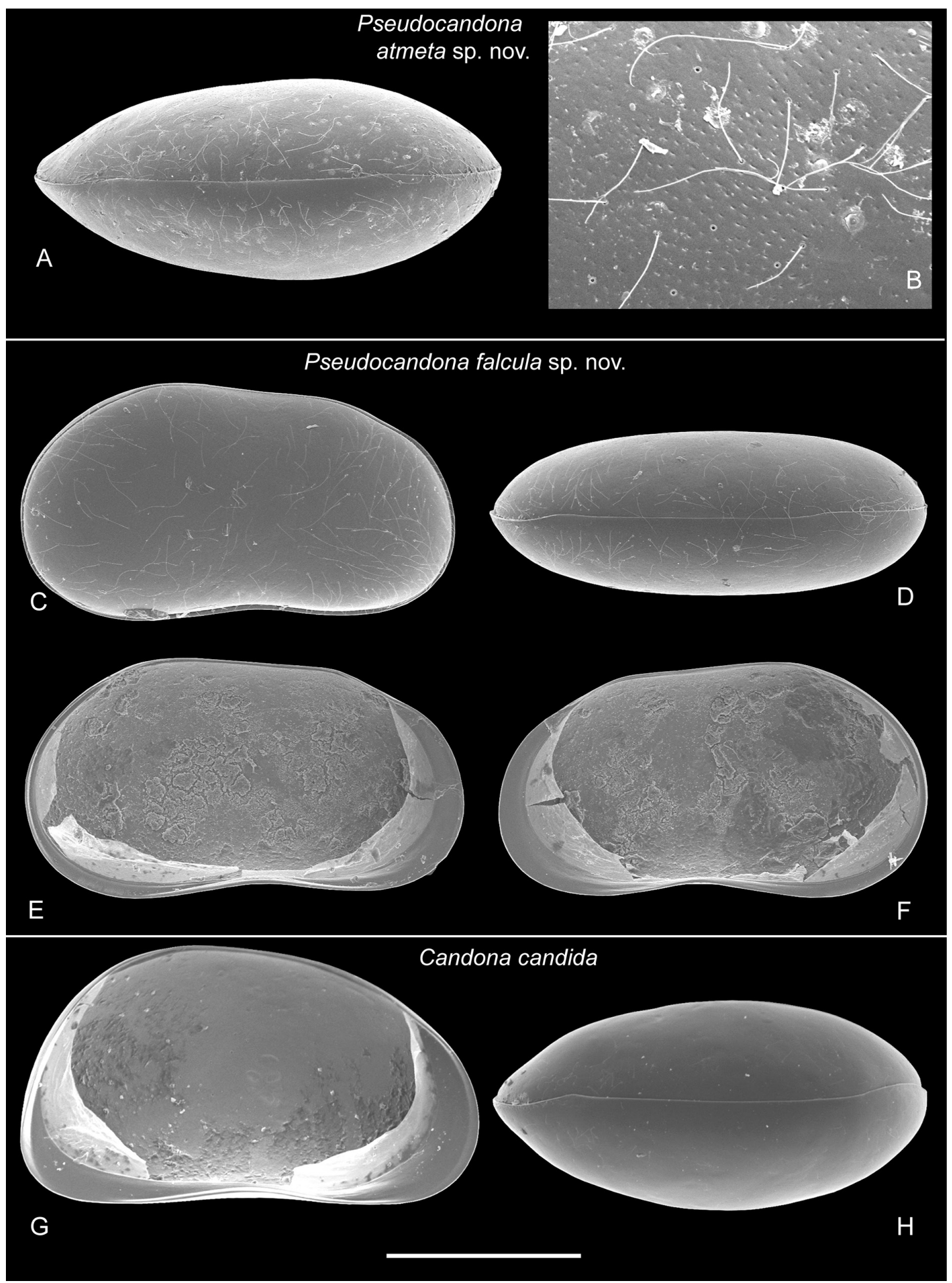

Fig. 7. A-B. Pseudocandona atmeta sp. nov. A. Dorsal view of male carapace, anterior to left (LBM 1430006272). B. Detail of external surface of male right valve (LBM 1430006272). C-F. Pseudocandona falcula sp. nov. C. Right view of female carapace (LBM 1430006278). D. Dorsal view of female carapace, anterior to left (LBM 1430006278). E. Internal view of female left valve (LBM 1430006277). F. Internal view of female right valve (LBM 1430006277). G-H. Candona candida (O.F. Müller, 1776) G. Internal view of female left valve. H. Dorsal view of female carapace, anterior to left. Scale bar: A, $\mathrm{C}-\mathrm{F}=500 \mu \mathrm{m} ; \mathrm{B}=134 \mu \mathrm{m} ; \mathrm{G}-\mathrm{H}=412 \mu \mathrm{m}$. 


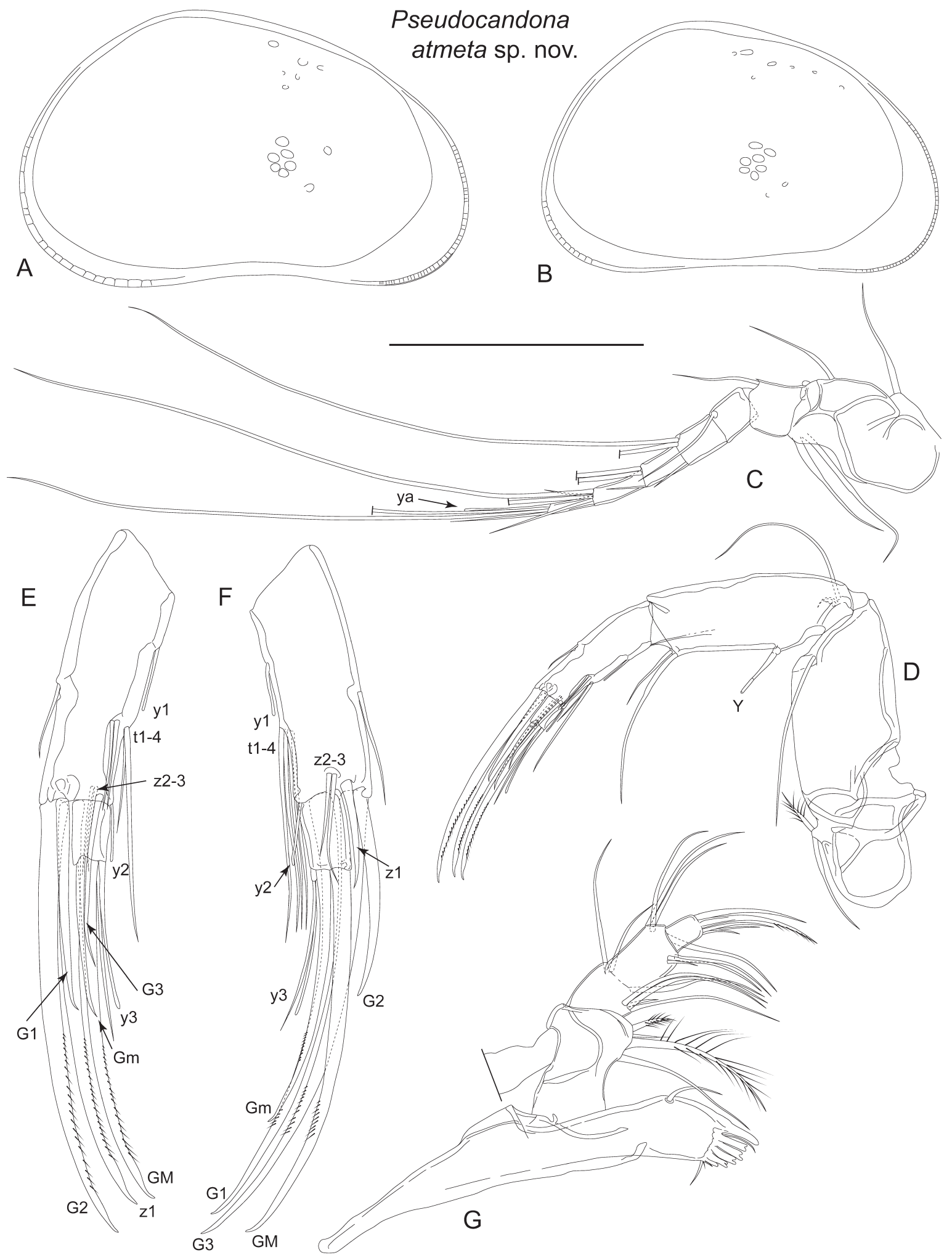

Fig. 8. Pseudocandona atmeta sp. nov. A. Internal view of male left valve (LBM 1430006270). B. Internal view of female left valve (LBM 1430006271). C. Male antennule (LBM 1430006270). D. Male antenna (LBM 1430006270). E. Detail of male antenna (LBM 1430006270). F. Detail of female antenna (LBM 1430006271). G. Male mandible (LBM 1430006270). Scale bar: A-B = $710 \mu \mathrm{m}$; $\mathrm{C}-\mathrm{D}, \mathrm{G}=200 \mu \mathrm{m} ; \mathrm{E}-\mathrm{F}=122 \mu \mathrm{m}$. 


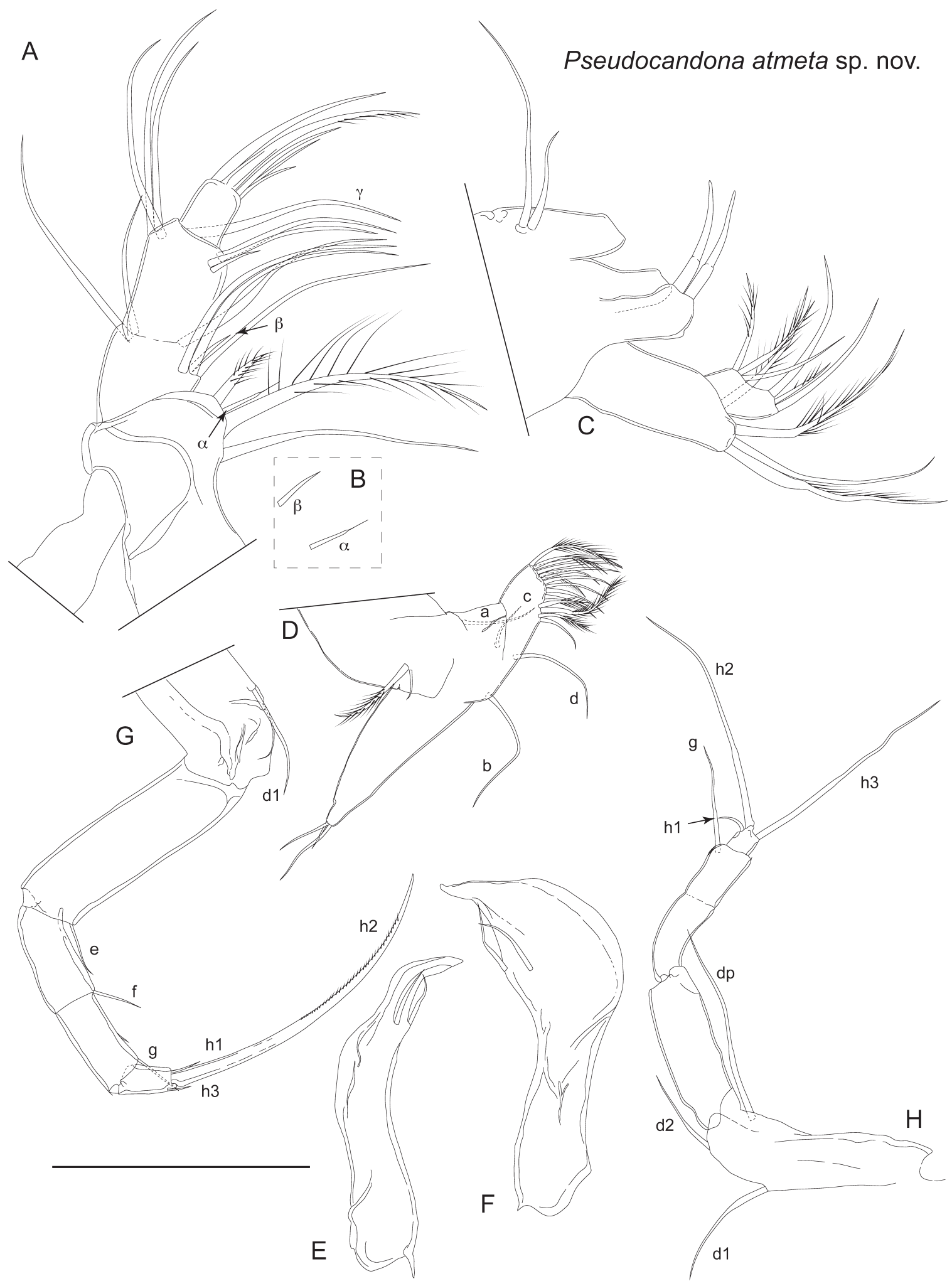

Fig. 9. Pseudocandona atmeta sp. nov. A. Male mandibular palp (LBM 1430006270). B. Detail of alpha and beta setae of mandibular palp (LBM 1430006270). C. Male maxillula (setae on endites not drawn) (LBM 1430006270). D. Female fifth limb (LBM 1430006271). E. Male left fifth limb palp (LBM 1430006270). F. Male right fifth limb palp (LBM 1430006270). G. Male sixth limb (LBM 1430006270). H. Male seventh limb (LBM 1430006270). Scale bar $=200 \mu \mathrm{m}$. 
Fifth limb of female (Fig. 9D) with one a-seta, and setae b, c and d present; b and d long. Endite with approximately 15 apical setae. Palp (endopodite) stout, terminating with three short setae of differing lengths. Branchial plate with one long and one short ray.

Sixth limb (Fig. 9G) first segment bearing long d1 seta. Setae e and f of second and third segments respectively, both less than half length of next respective segment. Fourth segment with g seta reaching to end of fifth segment. Fifth segment with short h1 seta, tiny h3 seta and well-developed claw h2.

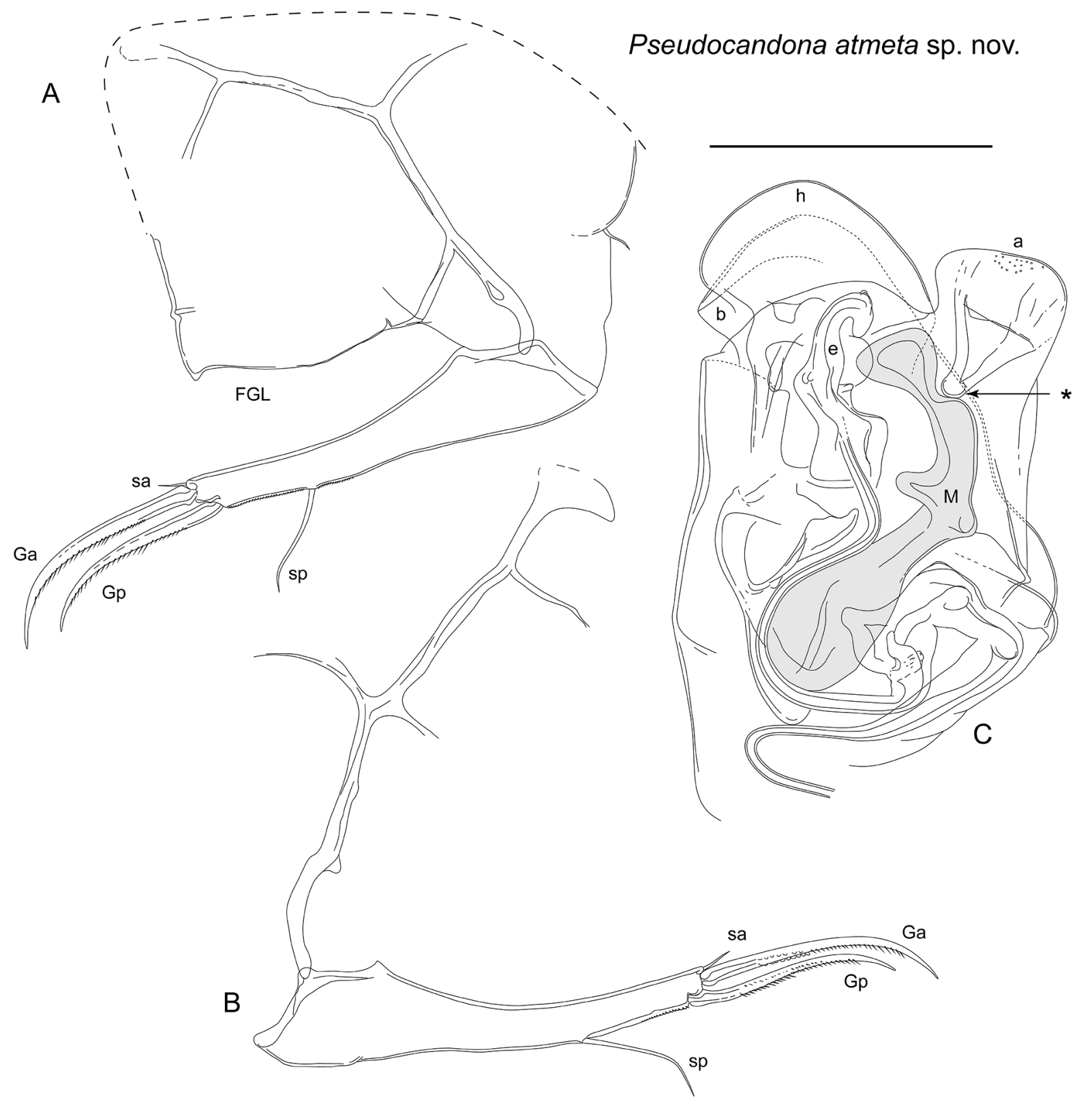

Fig. 10. Pseudocandona atmeta sp. nov. A. Female caudal ramus and genital lobe (LBM 1430006271) (FGL $=$ female genital lobe). B. Male caudal ramus (LBM 1430006270). C. Hemipenis (M-process shaded grey) (LBM 1430006270), asterisk marks protuberance of outer lobe (a) that contacts M-process. Scale bar $=200 \mu \mathrm{m}$. 
Seventh limb with five segments (Fig. 9H). First segment with long dp seta, medium-length d1 seta and shorter $\mathrm{d} 2$ seta. Second and third segments with no setae. Fourth segment with long g seta. Fifth segment approximately quadrate, h2 and h3 long and of equal length, h1 short, hook-like and reflexed.

Male caudal ramus (Fig. 10B) with inflated base, tapering distally, slightly curved to straight. Claw Ga straight proximally, curving distally. Claw Gp slightly shorter and thinner than Ga and slightly sinuous. Seta sa short, seta sp long, approximately two-thirds length of claw Gp. Caudal ramus attachment with rounded dorsal end, and with one posterior branch and two anterior branches on dorsal-most half.

Female caudal ramus (Fig. 10A) similar to male, but claws slightly more robust. Caudal ramus attachment with one posterior branch and two anterior branches, lowest of which curves to posterior edge of female genital lobe. Female genital lobe (Fig. 10A) large and triangular, with distinctive projection on apex.

Hemipenis (Fig. 10C) relatively large and wide. Outer lobe (a) tongue-like, with sub-quadrate distal end. Base of outer lobe with rounded, well chitinized protuberance that contacts M-process (marked with asterisk on Fig. 10C). Inner lobe (b) folded, producing angular projection on inner edge. Medial lobe (h) unevenly rounded, extending beyond both outer and inner lobes. M-process with rounded proximal base, tapering to curved middle section with small lobe on inner edge, and expanding distally to small, quadrate end. Notch on outer edge near tip contacting protuberance of outer lobe (a). Bursa copulatrix (e) elongate, tapering distally, and with backward curled tip.

\section{Remarks}

The carapace of Pseudocandona atmeta sp. nov. in lateral view is most similar to that of Pseudocandona marchica (Hartwig, 1899). However, these two species can be distinguished by the following features: the penultimate segment of the antennae is sub-divided and has male bristles in P. marchica, whereas Pseudocandona atmeta sp. nov. lacks this sub-division and male bristles; the Gp claw of the male's caudal ramus is reduced in P. marchica, whereas in Pseudocandona atmeta sp. nov. this claw is of typical length, albeit slender and slightly sinuous. The hemipenes of $P$. marchica are noticeably of different shape compared with those of Pseudocandona atmeta sp. nov., in particular the outer lobe (a) of Pseudocandona atmeta sp. nov. is more quadrate, and the inner lobe (b) smaller, while the entire body of the hemipenes are relatively wider compared with those of $P$. marchica; the female genital lobe is triangular in Pseudocandona atmeta sp. nov. whereas it is rounded in P. marchica. Other species of the rostrata-group have lower lateral views of the carapace, and all have differently shaped hemipenes and female genital lobes compared with Pseudocandona atmeta sp. nov. Additionally, Pseudocandona atmeta sp. nov. is the only member of the rostrata-group without a sub-division of the second endopodal segment of the male antennae and lacking male bristles.

\section{Ecology and distribution}

The type locality of Pseudocandona atmeta sp. nov. is a small boggy area covered by reeds and grasses, surrounded by trees. At the time of collecting, there was very little standing water, although the ground was sodden. Pseudocandona atmeta sp. nov. was found in a small, shallow pool amongst the vegetation, and in a small overgrown channel.

A second locality (also in Higashidori, Aomori Prefecture) yielded one male specimen of Pseudocandona atmeta sp. nov., together with Pseudocandona tenuirostris Hiruta \& Mawatari, 2013 (see under Pseudocandona tenuirostris for a description of this locality). Currently, this species is only known from the Higashidori region of Aomori Prefecture. 


\section{Pseudocandona falcula sp. nov. urn:1sid:zoobank.org:act:0138AA0F-95A0-4AED-AF47-9DD1CCCB63C1}

Figs 6C, 7C-F, 11-13

Pseudocandona sarsi - Smith \& Janz 2008: 2909, figs 17K-L, 25.

\section{Diagnosis}

Hinge straight, sloping to anterior region. Maximum height at posterior third. Posterior margin more inflated than anterior margin, both margins more or less evenly rounded. Calcified inner lamella narrow, wider anteriorly than posteriorly. Dorsal view compressed, with rounded anterior and posterior ends. Male antenna with sub-divided second endopodal segment, and with well-developed $\mathrm{t} 2$ and $\mathrm{t} 3$ male bristles. Female antennal claw G2 approximately half length of claw G3. Mandible with $3+1+$ beta setae on second segment of palp, and with long gamma seta and very short alpha and beta setae; beta shorter than alpha. Walking leg with long $\mathrm{d} 1 \mathrm{seta}$, and with e, and f setae shorter than next segment respectively. Seventh limb with five segments, terminating with long $\mathrm{h} 2$ and $\mathrm{h} 3$ setae of approximately equal length, and short, reflexed and curled h1 seta. Hemipenis with curved, relatively short M-process, outer lobe (a) large, and extending significantly beyond medial lobe (h), inner lobe (b) angular and folded.

\section{Etymology}

From the Latin falcula, meaning a "sickle" or "scythe", and referring to the shape of the M-process of the male sexual organ.

\section{Type material}

\section{Holotype}

$\delta$ (LBM 1430006275), dissected with appendages sealed in a glass slide and valves stored dry in a micropalaeontological cavity slide. Collected from the type locality on 27 Sep. 2004.

\section{Allotype}

o (LBM 1430006276), dissected with appendages sealed in a glass slide and valves stored dry in a micropalaeontological cavity slide. Collected from the type locality on 27 Sep. 2004.

\section{Paratypes}

1 (LBM 1430006277), dissected with appendages sealed in a glass slide and valves stored dry in a micropalaeontological cavity slide. 1 (LBM 1430006278), whole, stored dry in a micropalaeontological cavity slide. All collected from the type locality on 27 Sep. 2004.

\section{Type locality}

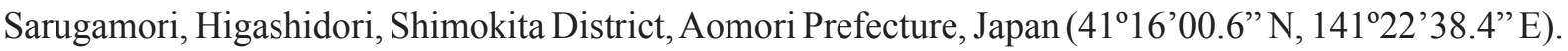
Boggy, marshy area with little standing water, lots of reeds, and sodden ground. Locality 4 on Fig. 1.

\section{Other material examined}

1 , from the type locality, collected 27 Sep. 2004.

\section{Description}

Carapace (Figs 7C-F, 11A-B) length 918-937 $\mu \mathrm{m}$, height 496-533 $\mu \mathrm{m}$. Maximum height at posterior third, hinge straight, sloping towards evenly rounded anterior margin. Posterior margin more inflated than anterior margin, and evenly curved. Ventral margin slightly concave. Inner calcified lamella relatively narrow, wider anteriorly than posteriorly. Six small adductor muscle scars in tight formation 
at mid-height, anterior of mid-length. Indistinct dorsal scars near dorsal margin. Female very similar to male. Colour, white. Surface covered with stiff setae.

Antennule with seven articulated segments (Fig. 11C). First segment large, supporting two setae on dorsal edge and two long setae on ventral-apical corner. Second and third segments quadrate each with one dorsal-apical seta. Fourth and fifth segments each with two long dorsal-apical setae and one short ventral-apical seta. Sixth segment with two long, one mid-length and one short apical setae. Final segment with two long and one short setae, and aesthetasc ya.

Male antenna with second endopodite segment sub-divided (Fig. 11D-E). Setae $\mathrm{t} 2$ and $\mathrm{t} 3$ represented by male bristles, both similar in morphology, but with $\mathrm{t} 2$ longer than $\mathrm{t} 3$, both terminating with small, triangular process. Seta $t 4$ tiny, protruding from near base of $\mathrm{t} 3$. Setae $\mathrm{z} 2$ and $\mathrm{z} 3$ very short, $\mathrm{z} 1$ represented by well-developed claw, slightly shorter than claw G2. Claw G1 less than half length of claw G2. Claw Gm on final segment half the length of claw GM. Female antennal claw G2 just under half length of G1, z1 stout and claw-like, less than half length of G2, setae z2 and z3 very short. Claw Gm more than half length of claw GM (Fig. 11F).

Mandibular palp (Fig. 12A-B) with four segments. Alpha seta of first segment short, and with very narrow, flagellum-like end. Inner edge of second segment with $3+1+$ beta arrangement of setae; seta beta shorter than alpha. Outer edge of second segment with two apical setae. Third segment with three long sub-apical setae on outer edge, and three long and one short setae arranged along apical edge; outermost gamma seta, long and without obvious setules. Final segment with robust seta on outer edge, thick claw-like seta in mid-apical position and three shorter setae on inner apical edge. Number of setae on branchial plate not observed. Mandibular coxa (Fig. 11G) with five well-developed teeth plus two much smaller, spine-like teeth.

Maxillula (Fig. 12C) palp first segment with three setae on apical outer margin, and one apical seta offset towards inner edge. Second segment with slightly stepped apical margin, with outer part more distal than inner part. Outer part of apical margin with two long and one short setae, and inner part with three mid-length setae. Branchial plate with morphology typical of subfamily.

Fifth limb male palps asymmetrical (Fig. 12D-E). Right palp rounded, helmet-shaped, more inflated than left. Left palp almost sub-triangular distally with angular outer margin, and almost straight inner margin.

Fifth limb of female (Fig. 12F) with long b and d setae, and one long a seta on basis. Endite with approximately nine apical setae, and four sub-apical setae on inner edge. Palp (endopodite) terminating with three setae on unequal lengths. Branchial plate consisting of two rays, one shorter and narrower than other.

Sixth limb (Fig. 12G) five-segmented, with first segment bearing $\mathrm{d} 1$ seta. Setae e and $\mathrm{f}$ of second and third segments respectively, both about half length of next respective segment. Fourth segment with $g$ seta reaching to end of fifth segment. Fifth segment with short h1 seta, tiny h3 seta and well-developed claw h2.

Seventh limb with five segments (Fig. 12H). First segment with long dp seta, and medium-length d1 and $\mathrm{d} 2$ setae. Second and third segments with no setae. Fourth segment with long g seta. Fifth segment approximately quadrate, $\mathrm{h} 2$ and $\mathrm{h} 3 \mathrm{long}$ and of approximately equal length, $\mathrm{h} 1$ short, hook-like and reflexed.

Caudal ramus (Fig. 13A-C) with inflated base, tapering distally, slightly curved to straight. Claw Ga straight proximally, curving distally. Claw Gp slightly shorter and thinner than Ga. Seta sa short, seta sp long, about $50 \%$ length of claw Gp. Caudal ramus attachment of male (Fig. 13B) with one posterior branch and two anterior branches on dorsal-most half. Female caudal ramus attachment (Fig. 13C) with one posterior branch and two anterior branches, lowest of which curves to posterior edge of female genital lobe. 


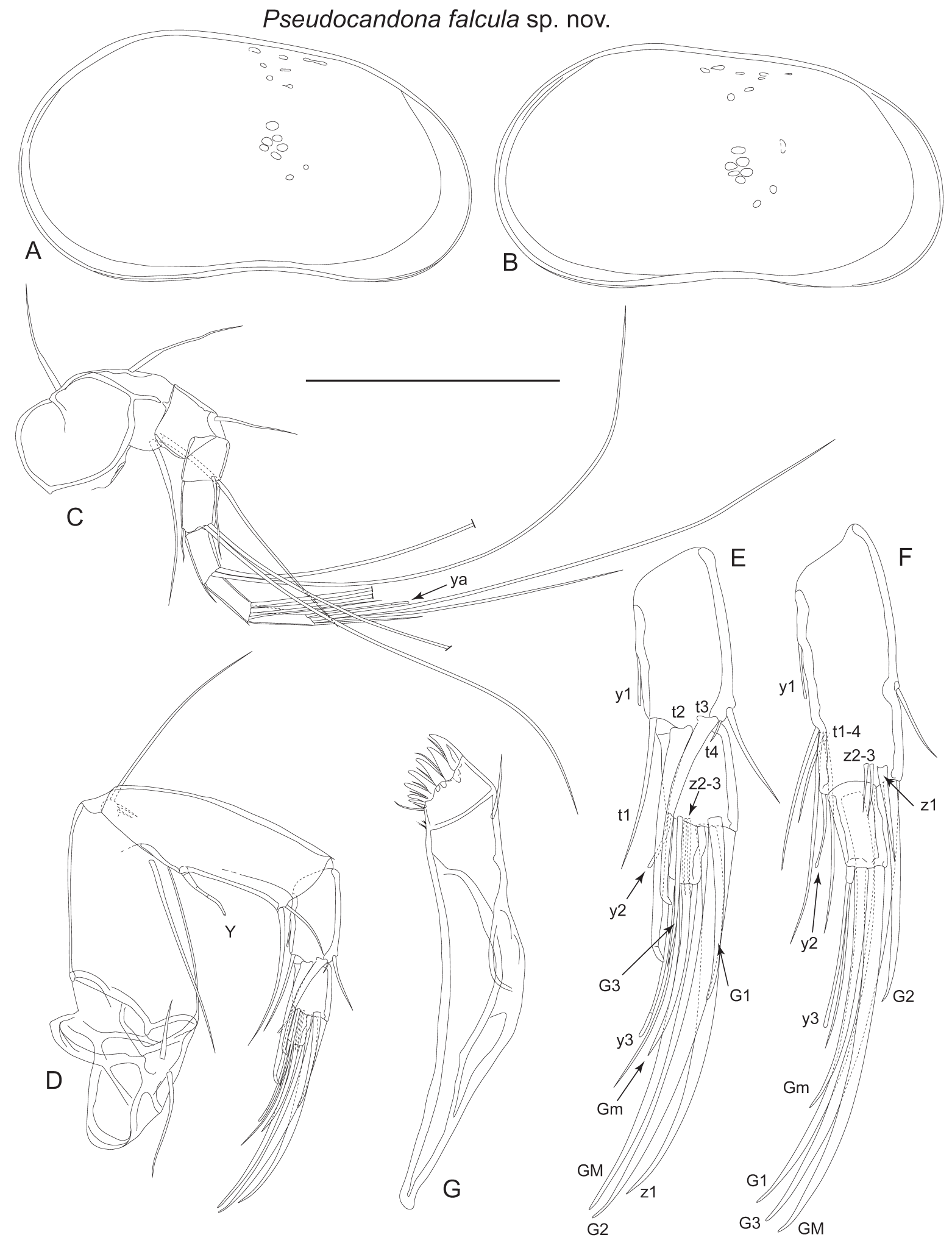

Fig. 11. Pseudocandona falcula sp. nov. A. Internal view of male left valve (LBM 1430006275). B. Internal view of female left valve (LBM 1430006276). C. Male antennule (LBM 1430006275). D. Male antenna (LBM 1430006275). E. Detail of male antenna (LBM 1430006275). F. Detail of female antenna (LBM 1430006276). G. Male mandibular coxa (LBM 1430006275). Scale bar: A-B = $543 \mu \mathrm{m}$; $\mathrm{C}-\mathrm{D}, \mathrm{G}=151 \mu \mathrm{m} ; \mathrm{E}-\mathrm{F}=82 \mu \mathrm{m}$. 


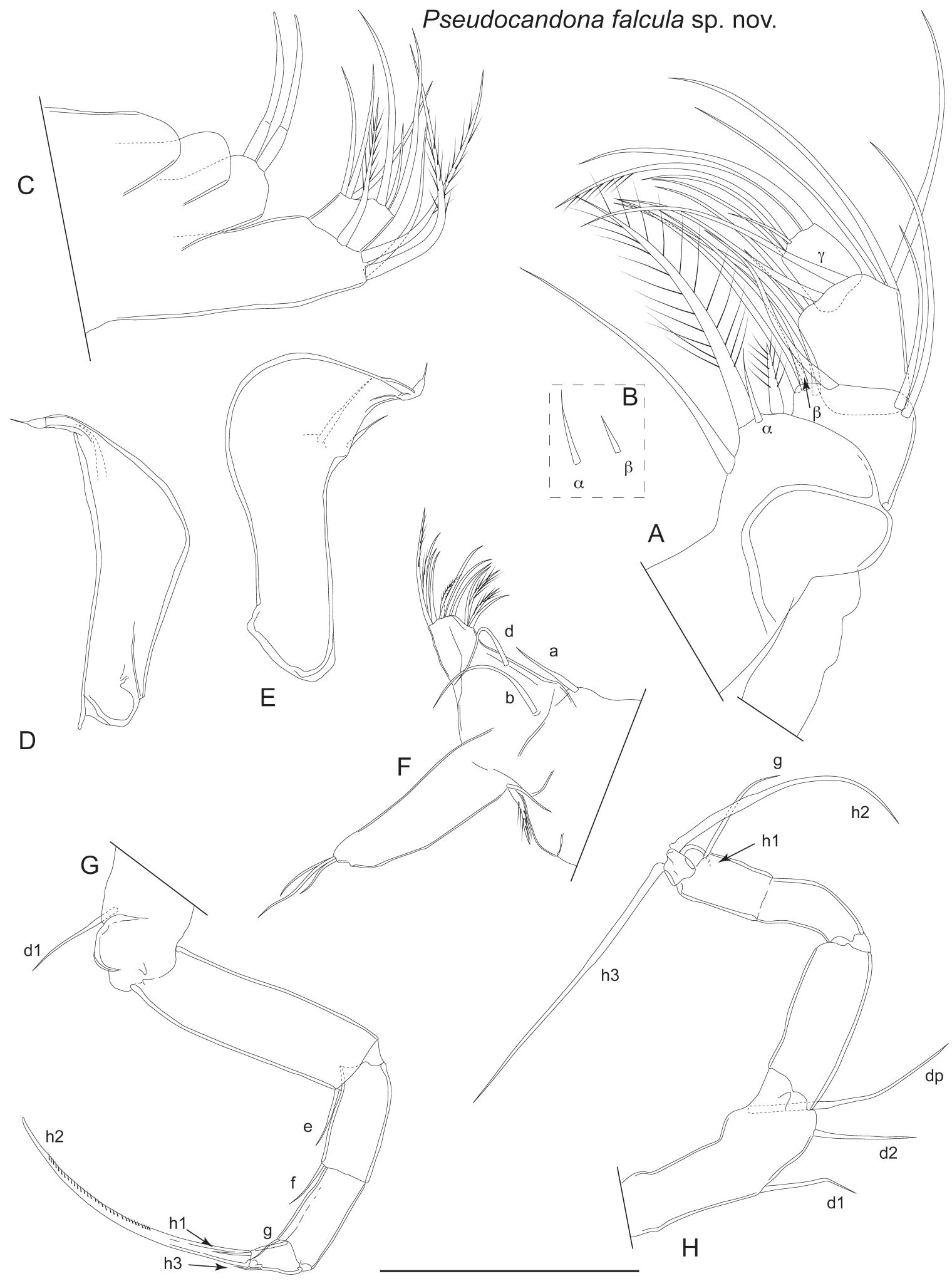

Fig. 12. Pseudocandona falcula sp. nov. A. Male mandibular palp (LBM 1430006275). B. Detail of alpha and beta setae of mandibular palp (LBM 1430006275). C. Male maxillula (setae on endites not drawn) (LBM 1430006275). D. Male left fifth limb palp (LBM 1430006275). E. Male right fifth limb palp (LBM 1430006275). F. Female fifth limb (LBM 1430006276). G. Male sixth limb (LBM 1430006275). H. Male seventh limb (LBM 1430006275). Scale bar: A-C $=82 \mu \mathrm{m} ; \mathrm{D}-\mathrm{H}=151 \mu \mathrm{m}$. 
Hemipenis (Fig. 13D) outer lobe (a) with truncated, sub-quadrate distal margin, extending beyond other two lobes. Medial lobe (h) with unevenly curved, rounded distal margin. Inner lobe (b) folded, triangular on inner edge, one part tongue-shaped, other quadrate. M-process small, rounded proximally, strongly curved and hook-like with lobe on inner edge. Bursa copulatrix (e) elongate with long finger distally.

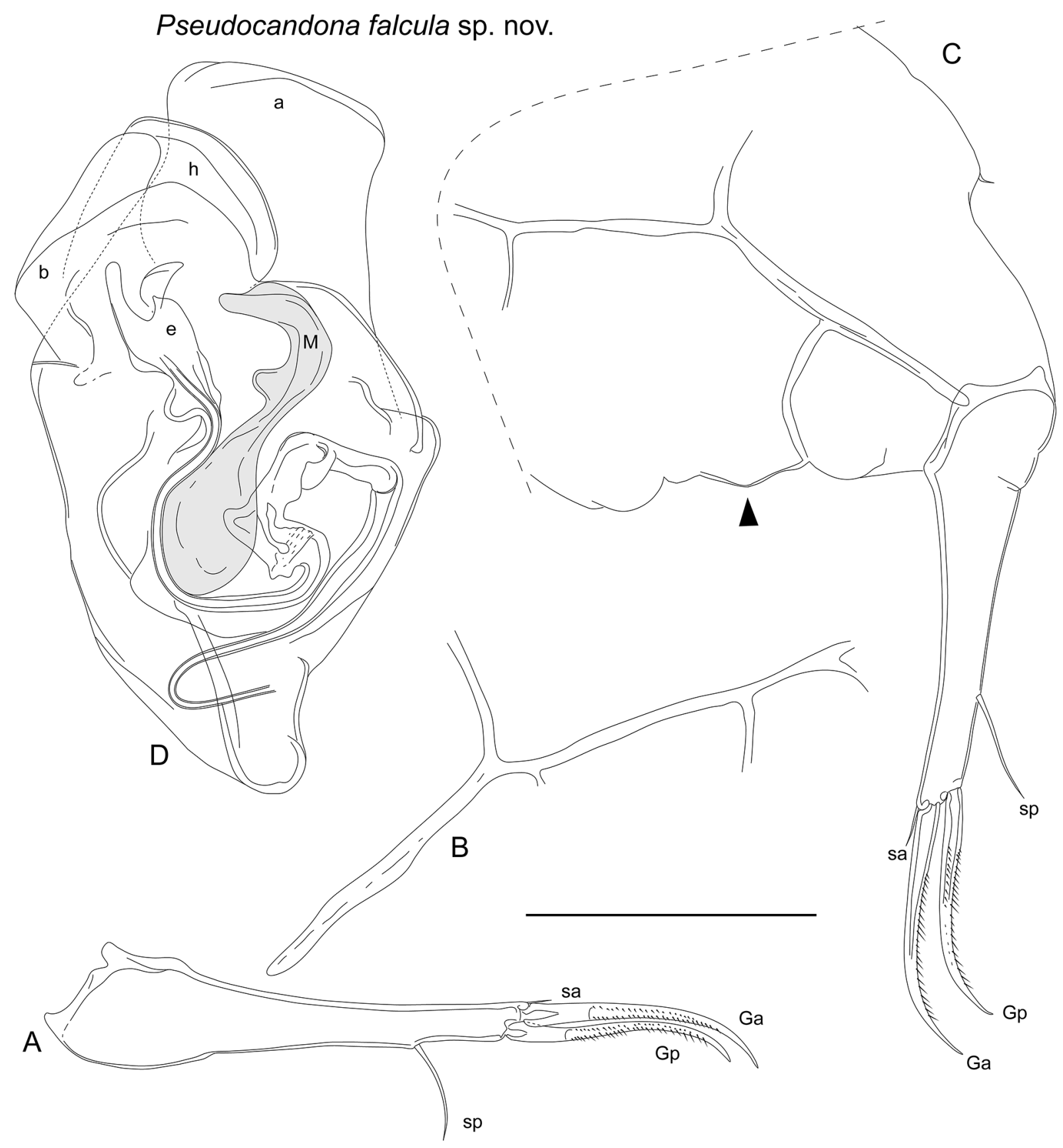

Fig. 13. Pseudocandona falcula sp. nov. A. Male caudal ramus (LBM 1430006275). B. Male caudal ramus attachment (LBM 1430006275). C. Female caudal ramus and genital lobe (LBM 1430006277), black triangle indicates rounded lobe (see text for details). D. Hemipenis (M-process shaded grey) (LBM 1430006275). Scale bar $=151 \mu \mathrm{m}$. 
Female genital lobe (Fig. 13C) with prominent projection with rounded apex. NB morphology noted before cover slip added. In material examined, lobes lightly sclerotized, with tendency to deform and break apart with addition of cover slip. In particular, rounded lobe (marked with triangle on Fig. 13C) less prominent and more spread out laterally after addition of cover slip.

\section{Remarks}

As noted above, the female genital lobe was noticeably deformed in shape in dissection slides after the cover slip had been lowered into position. The female genital lobe of candonids is widely used for the discrimination of species, but as noted by Namiotko \& Danielopol (2004), this feature is prone to deformation in dissection slides.

Pseudocandona falcula sp. nov. is similar to Pseudocandona sarsi (Hartwig, 1899) in the shape of the carapace in lateral view, although the dorsal view of $P$. sarsi is slightly wider and more pointed anteriorly and posteriorly. The male fifth limb palps are similar in both species, but the right palp of Pseudocandona falcula sp. nov. is more rounded on the outer edge than that of $P$. sarsi (which has a more angular outer edge). The seventh limbs of the two species are also similar, both with a short reflexed h1 seta on the final segment. Differences in the hemipenes include a larger outer lobe (a) in Pseudocandona falcula sp. nov., which clearly extends beyond the distal edge of the medial lobe (h). In P. sarsi the outer lobe is more offset to the outer edge of the hemipenes, has a more angular outer edge, and only slightly extends beyond the medial lobe. The M-processes of the two species are also different in shape.

The females of this species closely resemble the female specimens of P. sarsi reported from Lake Biwa (locality 8 on Fig. 1) by Smith \& Janz (2008). As no males were found from Lake Biwa, Smith \& Janz's (op. cit.) identification was tentative. Further investigation indicates that the carapaces and appendages of females from Lake Biwa very closely match material from the type locality, and it is concluded that the specimens from Lake Biwa are Pseudocandona falcula sp. nov.

\section{Ecology and distribution}

The type locality of this species is the same as for Pseudocandona atmeta sp. nov. (see below Pseudocandona atmeta sp. nov. for a description of that site). In Lake Biwa, the specimens were found at the water's edge in the root mat of a willow tree (Smith \& Janz 2008). To date, only a small number of females have been collected from Lake Biwa, in samples collected during Apr. 2005. It hasn't been collected since this time despite numerous samples taken at the same locality, and this may indicate that it was a temporary occurrence or it is rare in Lake Biwa. So far, this species is only known from Lake Biwa and the type locality.

Pseudocandona tenuirostris Hiruta \& Mawatari, 2013

Fig. 6D

Pseudocandona tenuirostris Hiruta \& Mawatari, 2013: 59-67, 72-73, figs 7-11, 18.

Pseudocandona rostrata - Matzke-Karasz et al. 2004: 1637, 1638, 1656, appendix 1.

\section{Material examined}

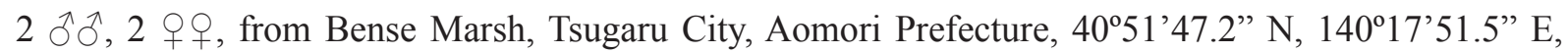
collected on 23 Sep. 2004. Locality 5 on Fig. 1.1 đ, 2 우, from Higashidori, Shimokita District, Aomori Prefecture, $41^{\circ} 19^{\prime} 31^{\prime \prime}$ N, $141^{\circ} 18^{\prime} 14.44^{\prime \prime}$ E, collected on 27 Sep. 2004. Locality 4 on Fig. 1. 


\section{Remarks}

This species is very similar to P. rostrata, with small differences in the shape of the medial lobe of the hemipenis and male fifth limb palps. Pseudocandona rostrata was reported from Hokkaido, Japan by Matzke-Karasz et al. (2004), but after a comparison of their specimens and P. tenuirostris it is concluded that they are the same. In particular, the medial lobe is slightly hook-shaped and thinner in $P$. tenuirostris compared with $P$. rostrata.

\section{Ecology and distribution}

In addition to the site mentioned in Matzke-Karasz et al. (2004), additional specimens were recovered from two localities in Aomori Prefecture (see material examined section above). At Bense Marsh, specimens were collected from sodden ground with small pools of water below a wooden walkway over the marsh. Water chemistry data at time of collecting was as follows: $\mathrm{pH} 5.24$, conductivity $27.5 \mu \mathrm{S} / \mathrm{cm}$, temperature $20.1{ }^{\circ} \mathrm{C}$. The Higashidori site consisted of a small boggy area covered in a thick growth of reeds, and surrounded by trees. At time of collecting, there was very little standing water, although the ground was sodden and mossy. A small, shallow hole was made in the sodden ground in order to sample the water. Water chemistry data at time of collecting was as follows: $\mathrm{pH} 5.98$, conductivity $24.1 \mu \mathrm{S} / \mathrm{cm}$, temperature $16.9^{\circ} \mathrm{C}$. Matzke-Karasz et al. (2004) reported this species from Kushiro Shitsugen National Park, which is a large marsh, and the nearby lower reaches of the Kottaro River, which flows through the marsh, in Hokkaido (locality 2 on Fig. 1). Also in Hokkaido, Hiruta \& Mawatari (2013) collected this species from Sarobetsu Marsh, Rishiri Rebun Sarobetsu National Park (locality 3 on Fig. 1). This suggests that this species has a preference for marshy, boggy areas in cooler parts of Japan. It is currently known from Aomori Prefecture in the northern part of Honshu, and Hokkaido.

Genus Candona Baird, 1845

Candona candida (O.F. Müller, 1776)

Fig. $7 \mathrm{G}-\mathrm{H}$

\section{Material examined}

16 우, from a creek leading to the south side of Akkeshi Lake, Akkeshi, Hokkaido, 4301'16.28” N, 14452'59.2" E, collected on 7 Sep. 2004 (locality 1 on Fig. 1). 13 우, from an artificial pond in

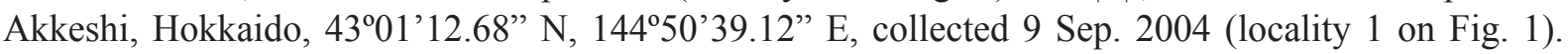
59 우, from pools in a shallow stream in the vicinity of Akkeshi Marine Biological Station, Akkeshi, Hokkaido, 4301'17.26” N, 14450'22.45” E, collected 9 Sep. 2004 (locality 1 on Fig. 1). 5 +, , from a pond and stream in the vicinity of Kiritappu Visitor Center, Kiritappu Marsh, Hamanaka, Akkeshi,

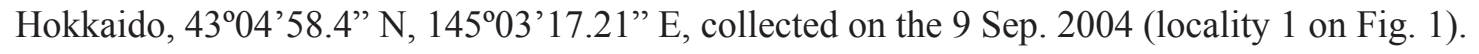

\section{Remarks}

A previous Japanese record of this species, from next to the visitor center of Kushiro Shitsugen National Park, Hokkaido, exists in the grey literature (a field guide for a post-symposium field excursion of the $14^{\text {th }}$ International Symposium on Ostracoda) (Hiruta \& Smith 2001). The additional records presented herein confirm its presence in Japan.

\section{Ecology and distribution}

The Japanese specimens of this species have been found in ponds, a creek, and shallow streams. Candona candida is found in Eurasia and North America, although rarer in the south (Meisch 2000), and hence its presence in the cooler part of Japan is not unexpected. It is notable, however, that so far Japanese records are restricted to the eastern part of Hokkaido. The nearest previous records of C. candida to eastern Hokkaido are from the vicinity of Peter the Great Bay, Far East of Russia (Schornikov 2004), 
approximately $1000 \mathrm{~km}$ due west, and NE Sakhalin Island, Russia (Schornikov \& Trebukhova 2001), approximately $1100 \mathrm{~km}$ north.

Genus Undulacandona Smith, 2011

Undulacandona colymba sp. nov. urn:1sid:zoobank.org:act:04046FDB-2E5C-4590-95EE-D74E97DE5837

Figs $14-17$

\section{Diagnosis}

Lateral view of carapace elongate with straight, almost level hinge. Male with anterior and posterior margins approximately equally rounded. Female with anterior margin more inflated than posterior one, with dorsal-posterior margin straight to slightly concave. Dorsal view with posterior and anterior ends compressed and pointed. Surface of carapace with fine longitudinal striations in both sexes. Antennule with six segments, first two of which partially fused forming one segment. Male antenna with well developed sexual bristles, $\mathrm{t} 2$ terminating in large, rounded structure. Female antenna with claw $\mathrm{G} 2$ as long as G1. Seta $\mathrm{h} 2$ on seventh limb claw-like and relatively long, almost four times longer than seta h1. Hp with medial lobe (h) curved and hook shaped, outer lobe (a) much larger than medial lobe, with wide base, widening distally to form flattened lobe with rounded distal end and with thin projection on apical outer side.

\section{Etymology}

From the Greek kolymbis, meaning a "diving bird", such as a grebe; the shape of the outer lobe (a) of the hemipenis is reminiscent of the head of a diving bird.

\section{Type material}

\section{Holotype}

त(LBM 1430006279), dissected with appendages sealed in a glass slide and valves stored dry in a micropalaeontological cavity slide. Collected from the type locality on 25 Sep. 2011.

\section{Allotype}

o (LBM 1430006280), dissected with appendages sealed in a glass slide and valves stored dry in a micropalaeontological cavity slide. Collected from the type locality on 25 Sep. 2011.

\section{Paratypes}

$1 \hat{\sigma}$, dead when collected but with appendages (LBM 1430006281), 1 q (LBM 1430006282), both dissected with appendages sealed in glass slides and valves stored dry in micropalaeontological cavity slides. 1 right valve (LBM 1430006283) and 1 whole $q$ carapace (LBM 1430006284), both stored dry in micropalaeontological cavity slides. All collected from the type locality on 25 Sep. 2011.

\section{Type locality}

Groundwater below agricultural land in Tsunosato, Kohoku-cho, Nagahama City, Shiga Prefecture, Japan, 35²6'57.0" N, 136 $11^{\circ}$ '58.6 E", approximately 440 meters from Lake Biwa and 80 meters from a small satellite lake (Nodanuma) (locality 7 on Fig. 1). Access to the groundwater is via hand pumps used for obtaining water for small-scale agriculture.

\section{Other material examined}

3 우, 1 r right valve, all from the type locality collected on 25 Sep. 2011. 


\section{Description}

Carapace length $755-778 \mu \mathrm{m}$, height 322-365 $\mu \mathrm{m}$ (Figs 14, 15A-E). Lateral view of carapace elongate with straight, level dorsal margin in central region, sloping down either side to anterior and posterior margins. Both anterior and posterior margins slightly unevenly curved, with maximum curvature below mid-height. Ventral margin straight to slightly sinuous. Posterior margin of male more inflated than that of female. Left valve overlaps right valve along ventral margin, and free margins in antero-dorsal and postero-dorsal regions; anterior and posterior margins with very little overlap. Dorsal view spindlelike, with pointed anterior and posterior ends. Internally, with more or less equally wide calcified inner lamella both anteriorly and posteriorly. Surface of valves covered with fine striations, more prominent in female compared with male. Colour whitish to translucent.

Antennule (Fig. 15F) with six segments, first two of which partially fused together, with possible articulation between them. Dorsal margin of first segment with one robust seta at apical end. Second segment with two long setae on apical ventral corner. Third segment with one apical-dorsal seta. Fourth segment elongate with one apical seta. Fifth segment elongate with two long and one shorter apical setae. Final segment small and elongate with long ya aesthetasc, two long and one short apical setae.

Antenna (Fig. 15G) exopodite consisting of rounded base with three very short setae. Y aesthetasc long and slender. Male with divided second endopodal segment, with two male bristles, $\mathrm{t} 2$ and $\mathrm{t} 3$ (Fig. 15I). Male bristle t 2 very thick and stout, approximately reaching to end of final segment, terminating with large, thin, flattened disc structure. Male bristle t3 stout, but thinner than $\mathrm{t} 2$, curved, slightly exceeding base of final segment, and with finely indented end. Male 44 seta tiny. $z 1$ and z2 both large claws, subequal in length to claw G2. G3 seta protruding to about end of final segment. Gm small and slender, about half-length of claw GM.

Female antenna with claw G2 equal in length to G1 and G3 (Fig. 15H). Claw Gm slender and about half length of claw GM (Fig. 15K). One specimen with one antenna with claw GM (outer-most one) shorter than Gm (Fig. 15J). Seta z3 absent.

Mandibular palp (Fig. 16A-B) first segment with reduced setulous S2 seta and short, slender alpha seta, together with long setulous S1 seta and one long seta on inner edge. Second segment with group of three long setae, together with slender beta seta and one slightly offset long seta $(3+1+$ beta $)$ on inner edge, and two setae on outer distal corner. Third segment with three sub-apical setae on outer edge and three stout setae and one short seta arranged along apical edge; outer-most one gamma seta. Final segment with two long, stout setae towards apical outer edge, and three apical, slender, shorter setae on inner edge. Number of setae on branchial plate not observed. Mandibular coxa typical of subfamily, with approximately 7 teeth (Fig. 16C).

Maxillula (Fig. 16D) first palp segment with three apical setae on outer corner, and one apical seta slightly offset towards inner edge. Final segment elongated, terminating with three long stout setae, and three shorter, more slender setae. Branchial plate with morphology typical of subfamily.

Male fifth limb palps (Fig. 16E-F) with fused terminal hooks, slightly asymmetrical. Palps slightly taper distally to long, curved hooks, each bearing two setae at base.

Female fifth limb small and stubby (Fig. 16G). Endite with approximately 12 setae, basis with one a-seta and c-seta. Palp very reduced, terminating with three short setae.

Sixth limb (Fig. 16H) very long and slender, with five segments. First and second segments with no setae. Third and fourth segments with very short $f$ and $g$ setae respectively. Final segment with very short h1 and h3 setae and long, slender h2 claw. 
Seventh limb (Fig. 16I) with four segments. First segment with d1 and d2 of approximately similar length, and seta dp longer. Second segment with no setae. Third segment with small $g$ seta. Final segment with short h1 seta, longer and claw-like h2 seta, about four times longer than h1, and a very long, reflexed h3 seta, approximately as long as the second and third segments combined.

Caudal ramus (Fig. 17C) short and stout and strongly curved, with wide proximal base tapering distally. Claws Ga and Gp similar in length and slightly sinuous. Seta sa tiny, seta sp short and located approximately at one-third length of ramus from distal end. Caudal ramus attachment long and branched.

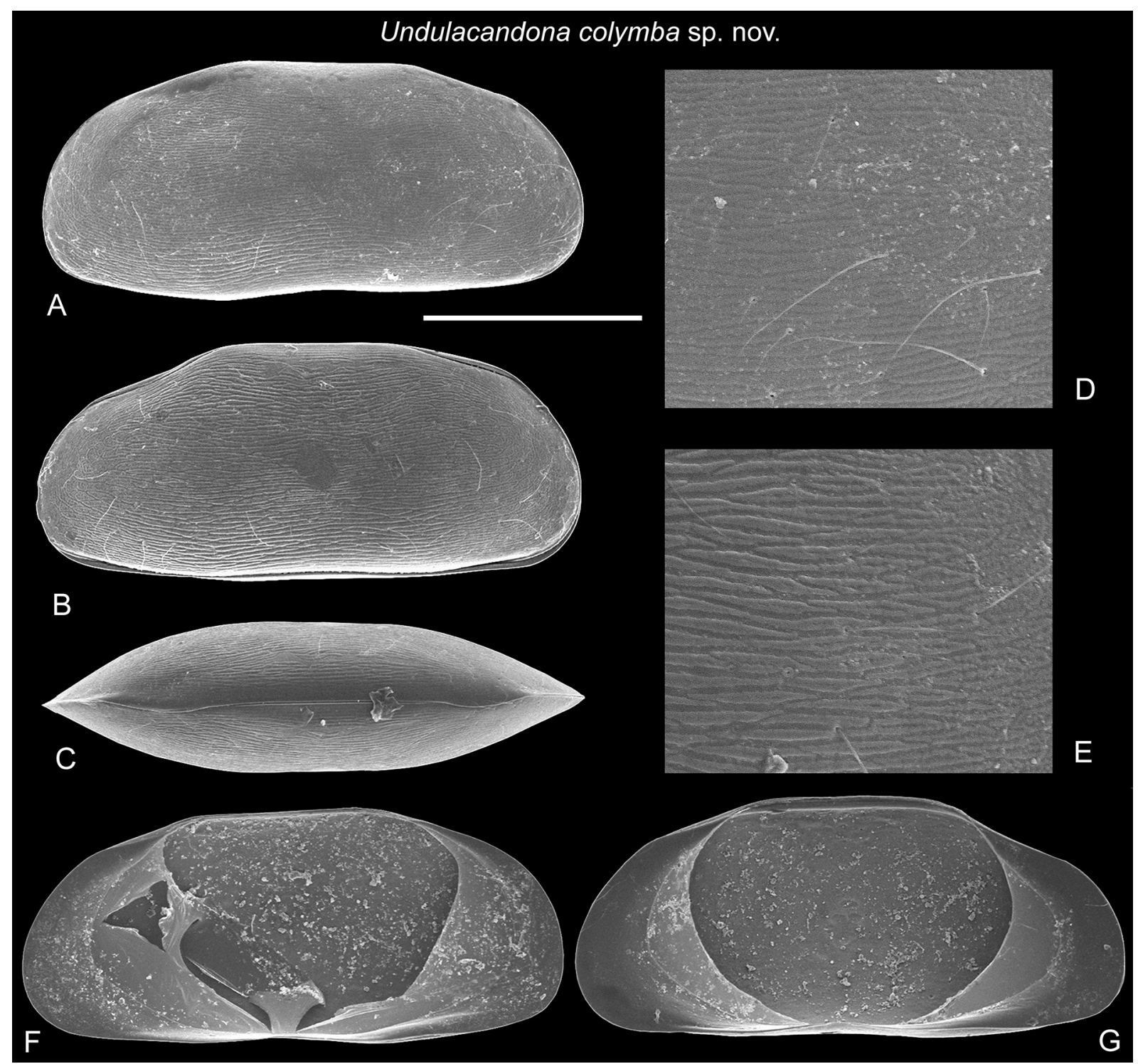

Fig. 14. Undulacandona colymba sp. nov. A. External view of male right valve (LBM 1430006283). B. Right view of female carapace (LBM 1430006284). C. Dorsal view of female carapace, anterior to right (LBM 1430006284). D. Detail of external surface of male right valve (LBM 1430006283). E. Detail of external surface of female right valve (LBM 1430006284). F. Internal view of male right valve (LBM 1430006283). G. Internal view of female right valve. Scale bar: A-C, $F-G=300 \mu \mathrm{m}$; $\mathrm{D}-\mathrm{E}=87 \mu \mathrm{m}$. 


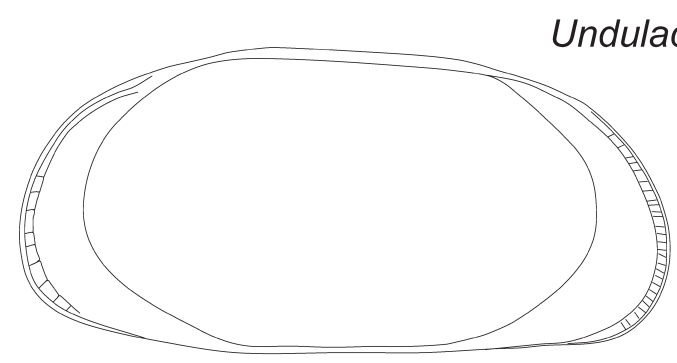

A

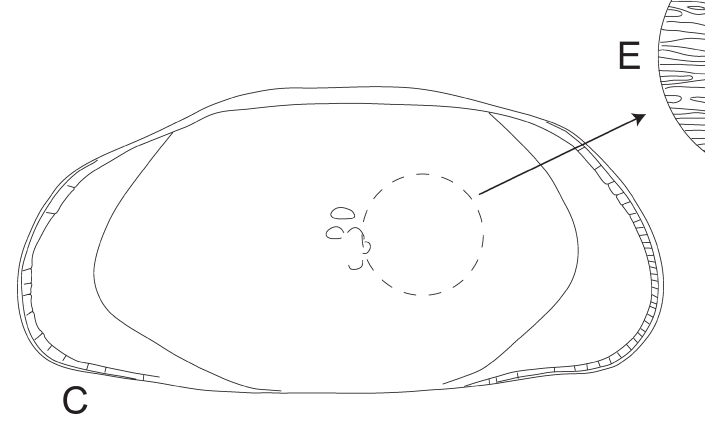

C

(
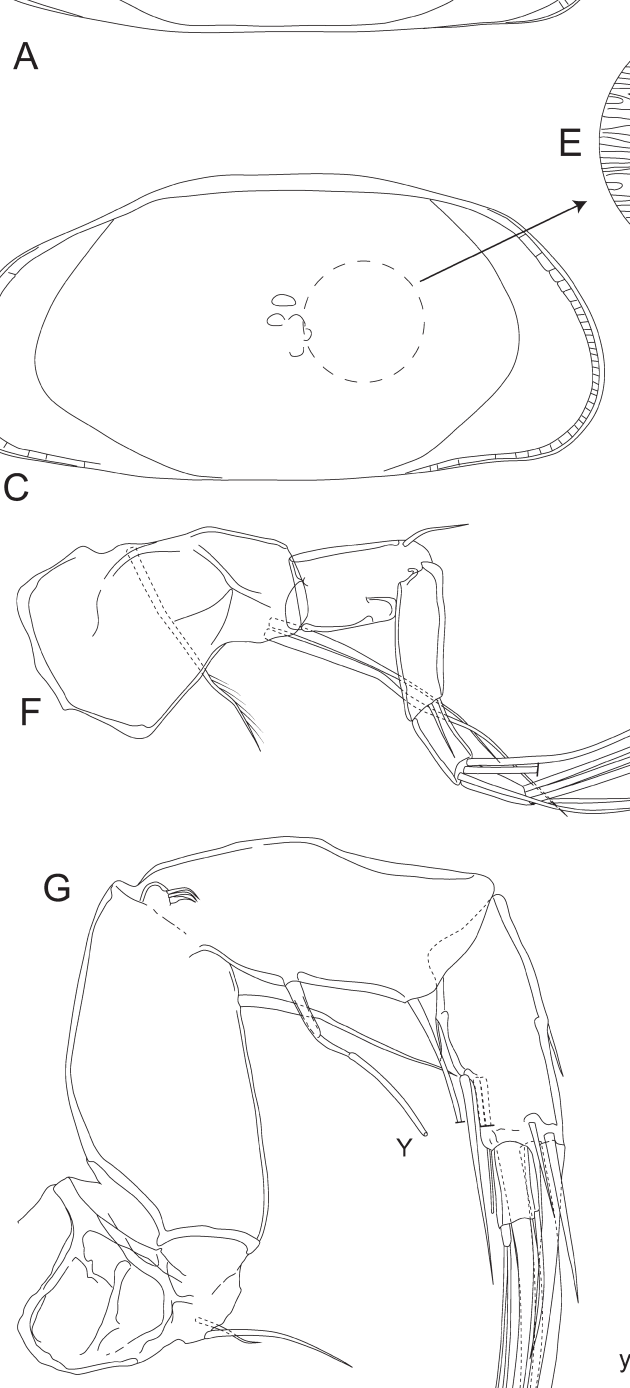

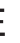
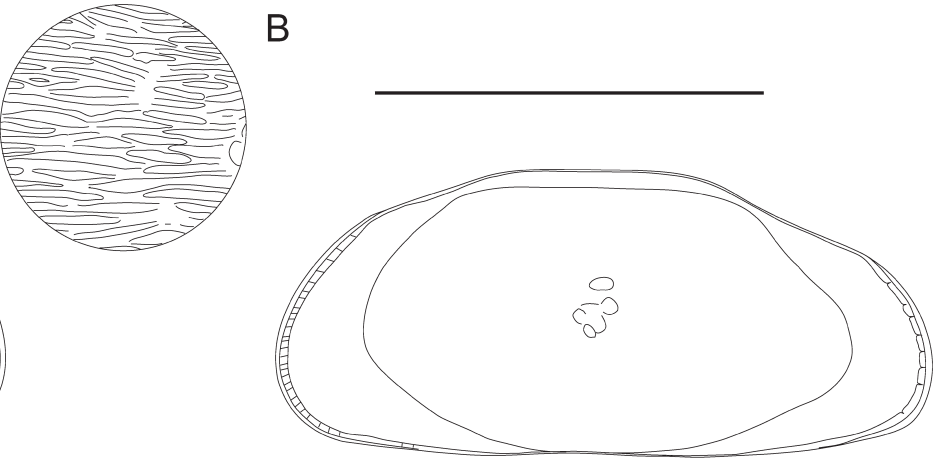

D

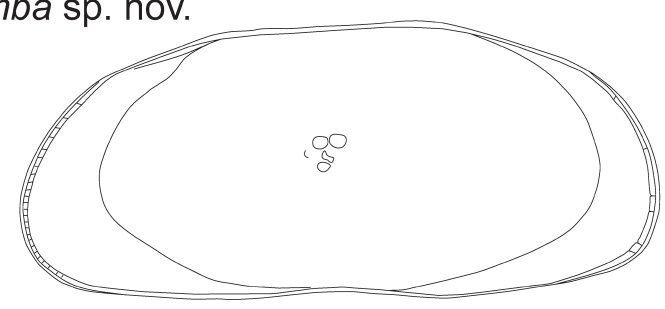

B
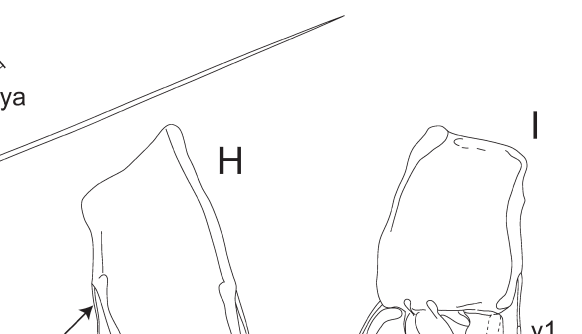

to

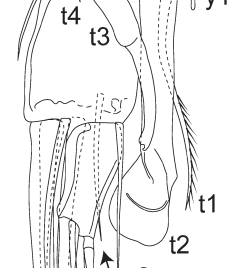

$z 1$

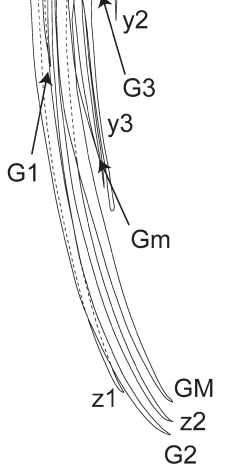

Fig. 15. Undulacandona colymba sp. nov. A. Internal view of male left valve (LBM 1430006279). B. Internal view of male right valve (LBM 1430006283). C. Internal view of female left valve (LBM 1430006280). D. Internal view of female right valve (LBM 1430006280). E. Detail of external surface of female right valve. F. Female antennule (LBM 1430006280). G. Female antenna (LBM 1430006280). H. Detail of female antenna (LBM 1430006280). I. Detail of male antenna (LBM 1430006279). J. Detail of female's final antennal segment (LBM 1430006280). K. Detail of female's final antennal segment. Scale bar: A-D $=464 \mu \mathrm{m} ; \mathrm{E}=232 \mu \mathrm{m} ; \mathrm{F}-\mathrm{G}=117 \mu \mathrm{m} ; \mathrm{H}-\mathrm{K}=92 \mu \mathrm{m}$. 


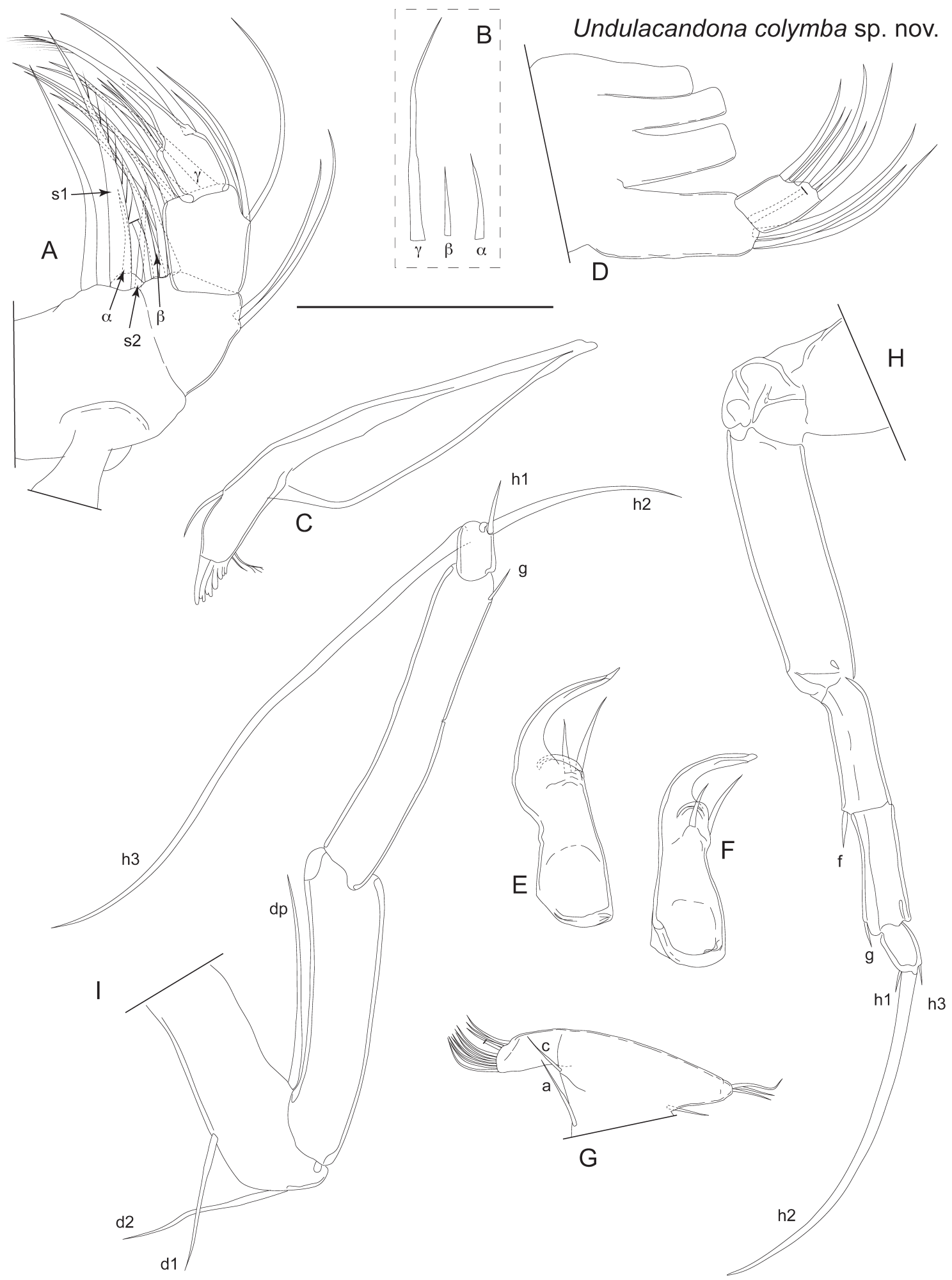

Fig. 16. Undulacandona colymba sp. nov. A. Female mandibular palp (LBM 1430006282). B. Alpha, beta and gamma setae of mandibular palp (LBM 1430006282). C. Female mandibular coxa (LBM 1430006282). D. Female maxillula (setae on endites not drawn) (LBM 1430006280). E-F. Left and right male fifth limb palps (LBM 1430006279). G. Female fifth limb (LBM 1430006282). H. Male sixth limb (LBM 1430006281). I. Female seventh limb (LBM 1430006280). Scale bar: A-B, D = $61 \mu \mathrm{m}$; C, $\mathrm{E}-\mathrm{I}=117 \mu \mathrm{m}$. 
Hemipenis (Fig. 17A) basal capsule elongated, roughly triangular-shaped, widening distally. Inner lobe (b) wide and rounded, with uneven distal margin. Medial lobe (h) curved and hook shaped, tapering distally to small, finger-like projection. Outer lobe (a) much larger than medial lobe, with wide base, widening distally to form flattened lobe with rounded distal end and with thin projection on apical outer side. Bursa copulatrix (e) s-shaped, tapering distally, with small, reflexed distal projection.

Zenker organ (Fig. 17B) relatively small, with wide central tube. Internally with three rosettes. Posterior end plate funnel-shaped, leading to distal section of vas deferens. Anterior end plate large and bulbous.

\section{Remarks}

One female has an antenna with the claw GM (the outer-most claw) on the final segment significantly shorter than the claw Gm (the claw next to it), whereas usually claw GM is larger than Gm. This is an unusual feature for the superfamily, but because it occurred in only one antenna in one specimen, it is probably an anomaly restricted to this one specimen. In addition to Undulacandona colymba sp. nov., two female specimens of an additional undescribed species of Undulacandona were collected. Due to the lack of males, this third species of the genus is not described herein.

This is the second species to be described in the genus Undulacandona; the first, Undulacandona spinula Smith, 2011, was found in a well below the city of Otsu in Shiga Prefecture (locality 9 on

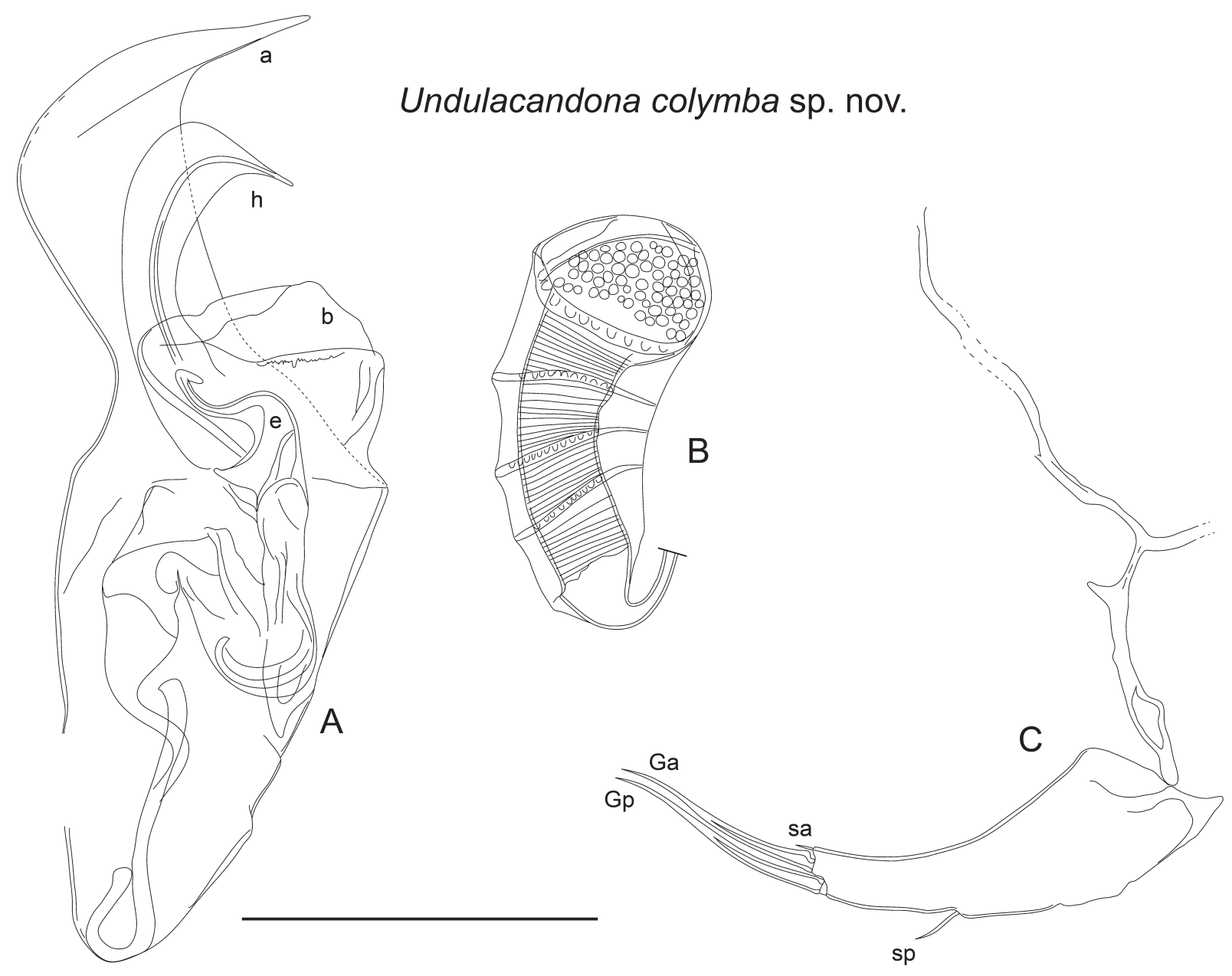

Fig. 17. Undulacandona colymba sp. nov. A. Hemipenis (LBM 1430006279). B. Zenker organ (LBM 1430006279). C. Male caudal ramus and attachment (LBM 1430006281). Scale bar $=117 \mu \mathrm{m}$. 
Fig. 1). The new species is easily distinguished from U. spinula by the shape of the carapace and the male hemipenes. In particular, the outer and medial lobes of the hemipenes of Undulacandona colymba sp. nov. are much larger and differently shaped from those of $U$. spinula.

\section{Ecology and distribution}

Both species of the genus are stygobionts, collected from groundwater via wells, in the case of Undulacandona colymba sp. nov. from a well with a hand pump attached in a vegetable patch. The underlying sediments are Pleistocene to Holocene alluvial sands and gravels, which surround Lake Biwa. Undulacandona colymba sp. nov. is currently only known from the type locality in Shiga Prefecture.

\section{Discussion}

Pseudocandona is now represented by six species in Japan: P. abei Smith \& Janz, 2008, Pseudocandona atmeta sp. nov., Pseudocandona becca sp. nov., Pseudocandona falcula sp. nov., P. pratensis (Hartwig, 1901), and P. tenuirostris. The three new species of Pseudocandona described herein and Pseudocandona tenuirostris all belong to the rostrata-group of the genus, characterized by a similar carapace shape and a group of three+one+beta setae on the inner edge of the second segment of the mandibular palp (Meisch 2000). In contrast, P. pratensis belongs to the compressa-group, while the position of $P$. abei is unclear, not fitting into the recent definition of Typhlocypris, nor the compressa- and rostrata-groups, which are Pseudocandona sensu stricto (Namiotko et al. 2014). All of the rostrata-group species in Japan and $P$. abei are currently only known from Japan, and are potentially endemic, while the sole representative of the compressa-group in Japan, P. pratensis, is known in Korea (albeit only by two female specimens) (Karanovic 2013), and Europe (see review of distribution in Meisch 2000). Pseudocandona atmeta sp. nov., Pseudocandona tenuirostris and Pseudocandona falcula sp. nov., have been found in marshes and boggy land in northern regions of Japan, although one of these, Pseudocandona falcula sp. nov., has also been found further south in Lake Biwa (Smith \& Janz 2008, as $P$. sarsi). It is uncertain if this southern record of Pseudocandona falcula sp. nov. represents a permanent population in the lake, as only a handful of specimens were recovered in 2004, and since that time, despite numerous samples taken by one of the authors (RJS) at the same locality, has not been encountered since. The significant number of migrating waterfowl that overwinter on Lake Biwa could be influencing the lake's ostracod fauna, by transporting eggs and individuals to the lake either attached externally or in digestive tracts, as suggested by previous authors for similar scenarios (e.g., Horne \& Smith 2004). If conditions in the lake are not suitable for completion of the species lifecycle, or if insufficient numbers were transported to form a viable reproducing population, such species could be transient visitors.

The hypogean genus Undulacandona now consists of two described species, although a third, currently undescribed species is known (see above). Furthermore, it is anticipated that the number of species in this genus will increase with additional sampling of groundwater habitats in Japan, habitats that still remain mostly unexplored in relation to their ostracod faunas. Undulacandona is therefore not one of the Candoninae's monotypic genera (see Danielopol et al. 2011) and is more diverse than 19 other Candoninae genera (representing half of all the genera in the subfamily).

The unusual features of this genus, such as the large disc-like structure on the male antenna, the very large seventh limbs that are used for locomotion rather than cleaning, the reduced Zenker organs with only three internal rosettes, and the small and stocky, but presumably still functioning caudal rami, suggests that this lineage is quite distant to other members of the subfamily. The lineage probably separated from other candonids a considerably long time ago, but without a known fossil record, its origin remains in the realm of speculation. The Lake Biwa region has a lacustrine history stretching back approximately four million years (Nakajima \& Nakai 1994), but the groundwater habitats that surround the lake today could potentially have older roots. 


\section{Acknowledgments}

We are grateful to Dan Danielopol (University of Graz, Austria) for his useful taxonomic advice, Shimpei Hiruta (Hokkaido University, Japan) for specimens of Pseudocandona tenuirostris and Mark Grygier (Lake Biwa Museum, Japan) for help in the field. We also thank Tadeusz Namiotko (University of Gdansk, Poland), David J. Horne (Queen Mary University of London, UK) and an anonymous reviewer for their useful comments. The material of Pseudocandona becca sp. nov. was collected by Mark Grygier and Tom Karanovic (Hanyang University, South Korea) as part of Lake Biwa Museum Comprehensive Research Project S06-02, and that of Undulacandona colymba sp. nov. as part of Lake Biwa Museum Cooperative Research Project K11-02.

\section{References}

Broodbakker N.W. \& Danielopol D.L. 1982. The Chaetotaxy of Cypridacea (Crustacea, Ostracoda) limbs: proposals for a descriptive model. Bijdragen tot de Dierkunde 52 (2): 103-120.

Danielopol D.L., Baltanás A., Morocutti U. \& Österreicher F. 2011. On the need to renew the taxonomic system of the Candoninae (non-marine Ostracoda, Crustacea). Reflexions from an analysis of data using the Yule Process. Geo-Eco-Marina 17: 5-20.

Danielopol D.L., Namiotko T. \& Meisch C. 2012. Marmocandona nov. gen. (Ostracoda, Candoninae), with comments on the contribution of stygobitic organisms to micropalaeontological studies. Kölner Forum für Geologie und Paläontologie 21: 13-16.

Delorme L.D. 1970. Freshwater ostracodes of Canada. Part III. Family Candonidae. Canadian Journal of Zoology 48 (5): 1099-1127. http://dx.doi.org/10.1139/z70-194

Gutentag E.D. \& Benson R.H. 1962. Neogene (Plio-Pleistocene) fresh-water ostracodes from the central high plains. Bulletin 157, Reports of Studies 4, Kansas Geological Survey, University of Kansas, Lawrence.

Higuti J. \& Martens K. 2014. Five new species of Candoniae (Crustacea, Ostracoda) from the alluvial valley of the Upper Paraná River (Brazil, South America). European Journal of Taxonomy 106: 1-36. http://dx.doi.org/10.5852/ejt.2014.106

Hiruta S.F. \& Mawatari S.F. 2013. Ostracods (Crustacea) from Sarobetsu Marsh, northern Hokkaido, Japan: taxonomy and phenology with description of Pseudocandona tenuirostris sp. nov. Species Diversity 18 (1): 57-74. http://dx.doi.org/10.12782/sd.18.1.057

Hiruta S. \& Smith R.J. 2001. Living freshwater and shallow marine Ostracoda in Eastern Hokkaido, Japan (Field excursion E). In: Ikeya N. (ed.) Guidebook of Excursions of the 14th International Symposium on Ostracoda: 107-125. Shizuoka University, Shizuoka.

Horne D.J. \& Smith R.J. 2004. First British record of Potamocypris humilis (Sars, 1924), a freshwater ostracod with a disjunct distribution in northern Europe and southern Africa. Bollettino della Societa Paleontologica Italiana 43: 297-306.

Karanovic I. 2006. Recent Candoninae (Crustacea, Ostracoda) of North America. Records of the Western Australian Museum, Supplement 71, Western Australian Museum, Perth.

Karanovic I. 2013. Earicandona, new genus and the first record of Typhlocypris pratensis (Crustacea, Ostracoda) from South Korea. Journal of Species Research 2 (2): 145-158. http://dx.doi.org/10.12651/ JSR.2013.2.2.145

Karanovic I. \& Lee W. 2012. A review of candonid ostracods (Crustacea: Ostracoda: Podocopida) from East Asia, with descriptions of five new species from South Korea. Zootaxa 3368: 7-49. 
Martens K. 1987. Homology and functional morphology of the sexual dimorphism in the antenna of Sclerocypris Sars, 1924 (Crustacea, Ostracoda, Megalocypridinae). Bijdragen tot de Dierkunde 57 (2): 183-190.

Martens K. \& Savatenalinton S. 2011. A subjective checklist of the Recent, free-living, non-marine Ostracoda (Crustacea). Zootaxa 2855: 1-79.

Martens K., Schön I., Meisch C. \& Horne D.J. 2008. Global diversity of ostracods (Ostracoda, Crustacea) in freshwater. Hydrobiologia 595 (1): 185-193. http://dx.doi.org/10.1007/s10750-007-9245-4

Matzke-Karasz R., Smith R.J. \& Homma M. 2004. Cyclocypris diebeli Absolon, 1973 (Ostracoda, Crustacea), extinct in Europe, extant in Japan. Journal of Natural History 38 (13): 1635-1663. http:// dx.doi.org/10.1080/0022293031000156178

McKenzie K.G. 1972. Results of the speleological survey in South Korea 1966. XXII. Subterranean Ostracoda from South Korea. Bulletin of the National Science Museum Tokyo 15: 155-166.

Meisch C. 2000. Freshwater Ostracoda of Western and Central Europe. Süßwasserfauna von Mitteleuropa 8/3. Spektrum Akademischer Verlag, Heidelberg.

Nakajima T. \& Nakai K. 1994. Lake Biwa. In: Martens K., Goddeeris B. \& Coulter G. (eds) Speciation in ancient lakes: 43-54. Advances in Limnology 44, E. Schweizerbart'sche Verlagsbuchhandlung, Stuttgart.

Namiotko T. \& Danielopol D.L. 2004. Review of the eremita species-group of the Pseudocandona Kaufmann (Ostracoda, Crustacea), with the description of a new species. Revista Española de Micropaleontología 36: 109-125.

Namiotko T., Danielopol D.L., Meisch C., Gross M. \& Mori N. 2014. Redefinition of the genus Typhlocypris Vejdovský, 1882 (Crustacea, Ostracoda, Candonidae). Crustaceana 87 (8-9): 952-984. http://dx.doi.org/10.1163/15685403-00003338

Okubo I. 1990. Sixteen species of freshwater Ostracoda from Japan. Bulletin of the Biogeographical Society of Japan 45 (6): 39-50.

Okubo I. 2004. Nihon tansui san kaimijinko rui ni tsuite. Kabushikigaisha Sanmon Insatsusho, Okayama. [In Japanese, privately published].

Schornikov E.I. \& Trebukhova Y.A. 2001. Ostracods of brackish and fresh waters of southwestern coast of Peter the Great Bay. In: Kasyanov V.L., Vaschenko M.A. \& Pitruk D.L. (eds) The State of Environment and Biota of the Southwestern Part of Peter the Great Bay and the Tumen River Mouth: 56-85. Dalnauka, Vladivostok. [In Russian]

Schornikov E.I. 2004. Crustacea: Ostracoda. In: Tyurin A.N. \& Drozdov A.L. (eds) Far-Eastern Marine Biospherical Reserve. Biota. V. 2: 458-465. Dalnauka, Vladivostok.

Smith R.J. 2011. Groundwater, spring and interstitial Ostracoda (Crustacea) from Shiga Prefecture, Japan, including descriptions of three new species and one new genus. Zootaxa 3140: 15-37.

Smith R.J. \& Janz H. 2008. Recent species of the Family Candonidae (Ostracoda, Crustacea) from the ancient Lake Biwa, Central Japan. Journal of Natural History 42 (45-46): 2865-2922. http://dx.doi. org $/ 10.1080 / 00222930802361030$

Smith R.J. \& Kamiya T. 2006. Six new species of fresh and brackish water ostracods (Crustacea) from Yakushima, Southern Japan. Hydrobiologia 559: 331-355. http://dx.doi.org/10.1007/s10750-005-0946-2

Smith R.J., Matzke-Karasz R., Kamiya T. \& De Deckker P. 2014. Sperm lengths of non-marine cypridoidean ostracods (Crustacea). Acta Zoologica: http://dx.doi.org/10.1111/azo.12099 
Tanaka H., Kotorii H., Yokozawa K., Wakabayashi F., Kimoto K. \& Sano K. 2015. Distribution and occurrence of freshwater Ostracoda (Crustacea) from southwest region of Mt. Fuji. TAXA, Proceedings of the Japanese Society of Systematic Zoology 38: 26-41. [In Japanese]

Yu N., Zhao Q., Li E., Chen S. \& Chen L. 2009. An updated and annotated checklist of recent nonmarine ostracods from China. Zootaxa 2067: 29-50.

Manuscript received: 29 March 2015

Manuscript accepted: 9 June 2015

Published on: 7 September 2015

Topic editor: Rudy Jocqué

Desk editor: Charlotte Thionois

Printed versions of all papers are also deposited in the libraries of the institutes that are members of the EJT consortium: Muséum national d'Histoire naturelle, Paris, France; Botanic Garden Meise, Belgium; Royal Museum for Central Africa, Tervuren, Belgium; Natural History Museum, London, United Kingdom; Royal Belgian Institute of Natural Sciences, Brussels, Belgium; Natural History Museum of Denmark, Copenhagen, Denmark. 